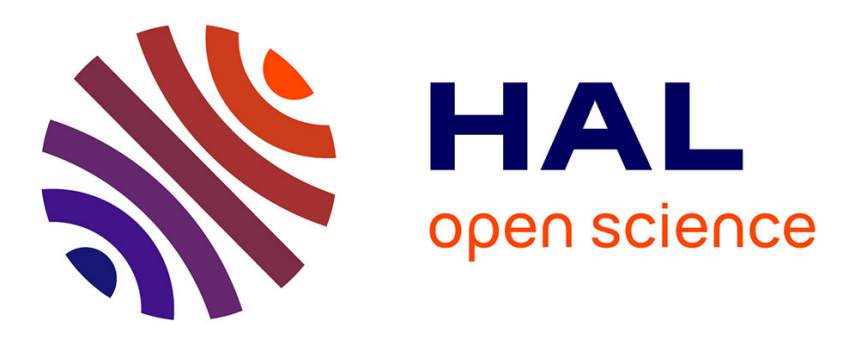

\title{
Targeting oxidative stress, a crucial challenge in renal transplantation outcome
}

Romain Carcy, Marc Cougnon, Mallorie Poet, Manon Durandy, Antoine

Sicard, Laurent Counillon, Nicolas Blondeau, Thierry Hauet, Michel Tauc, Didier Pisani

\section{To cite this version:}

Romain Carcy, Marc Cougnon, Mallorie Poet, Manon Durandy, Antoine Sicard, et al.. Targeting oxidative stress, a crucial challenge in renal transplantation outcome. Free Radical Biology and Medicine, 2021, 169, pp.258-270. 10.1016/j.freeradbiomed.2021.04.023 . hal-03205993

\section{HAL Id: hal-03205993 https://hal.science/hal-03205993}

Submitted on 22 Apr 2021

HAL is a multi-disciplinary open access archive for the deposit and dissemination of scientific research documents, whether they are published or not. The documents may come from teaching and research institutions in France or abroad, or from public or private research centers.
L'archive ouverte pluridisciplinaire HAL, est destinée au dépôt et à la diffusion de documents scientifiques de niveau recherche, publiés ou non, émanant des établissements d'enseignement et de recherche français ou étrangers, des laboratoires publics ou privés. 


\section{Targeting oxidative stress, a crucial challenge in renal transplantation outcome}

Carcy Romain ${ }^{1,2,3 \$}$, Cougnon Marc ${ }^{1,3, \$}$, Poet Mallorie ${ }^{1,3}$, Durandy Manon ${ }^{1,3}$, Sicard Antoine $^{1,3,4,5}$, Counillon Laurent ${ }^{1,3}$, Blondeau Nicolas ${ }^{6}$, Hauet Thierry ${ }^{7}$, Tauc Michel ${ }^{1,3}$ and Pisani Didier F1,3,.

1. Université Côte d'Azur, CNRS, LP2M, Nice, France.

2. CHU Nice, Hôpital Pasteur 2, Service de Réanimation Polyvalente et Service de Réanimation des Urgences Vitales, Nice, France.

3. Laboratories of Excellence Ion Channel Science and Therapeutics, Nice, France.

4. CHU Nice, Hôpital Pasteur 2, Service de Néphrologie-Dialyse-Transplantation, Nice, France.

5. Clinical Research Unit of Université Côte d'Azur (UMR2CA).

6. Université Côte d'Azur, CNRS, IPMC, Valbonne, France.

7. Université de Poitiers, INSERM, IRTOMIT, CHU de Poitiers, La Milétrie, Poitiers, France.

*. Corresponding: Université Côte d'Azur, CNRS, Laboratoire de Physiomédecine Moléculaire, UMR7370, Faculté de médecine, 28 avenue de Valombrose, 06107 Nice cedex, France. didier.pisani@univ-cotedazur.fr.

$\$$. equal contribution 


\begin{abstract}
Disorders characterized by ischemia/reperfusion $(\mathrm{I} / \mathrm{R})$ are the most common causes of debilitating diseases and death in stroke, cardiovascular ischemia, acute kidney injury or organ transplantation. In the latter example the I/R step defines both the amplitude of the damages to the graft and the functional recovery outcome. During transplantation the kidney is subjected to blood flow arrest followed by a sudden increase in oxygen supply at the time of reperfusion. This essential clinical protocol causes massive oxidative stress which is at the basis of cell death and tissue damage. The involvement of both reactive oxygen species (ROS) and nitric oxides (NO) has been shown to be a major cause of these cellular damages. In fact, in non-physiological situations, these species escape endogenous antioxidant control and dangerously accumulate in cells. In recent years, the objective has been to find clinical and pharmacological treatments to reduce or prevent the appearance of oxidative stress in ischemic pathologies. This is very relevant because, due to the increasing success of organ transplantation, clinicians are required to use limit organs, the preservation of which against oxidative stress is crucial for a better outcome. This review highlights the key actors in oxidative stress which could represent new pharmacological targets.
\end{abstract}

keywords: Hypoxia, anoxia, kidney, oxidative stress, NO, ROS.

fundings: This work was supported by a grant from the Société de Réanimation de Langue Française (SRLF) and a grant (project KIRI) from the Agence Nationale pour la Recherche (ANR).

\title{
highlights:
}

- Ischemia/reperfusion generates oxidative stress from several targetable pathways.

- Various pharmacological approaches to limit oxidative stress are under investigation.

- Combining several approaches would be beneficial to kidney transplant outcome. 
Graphical abstract.

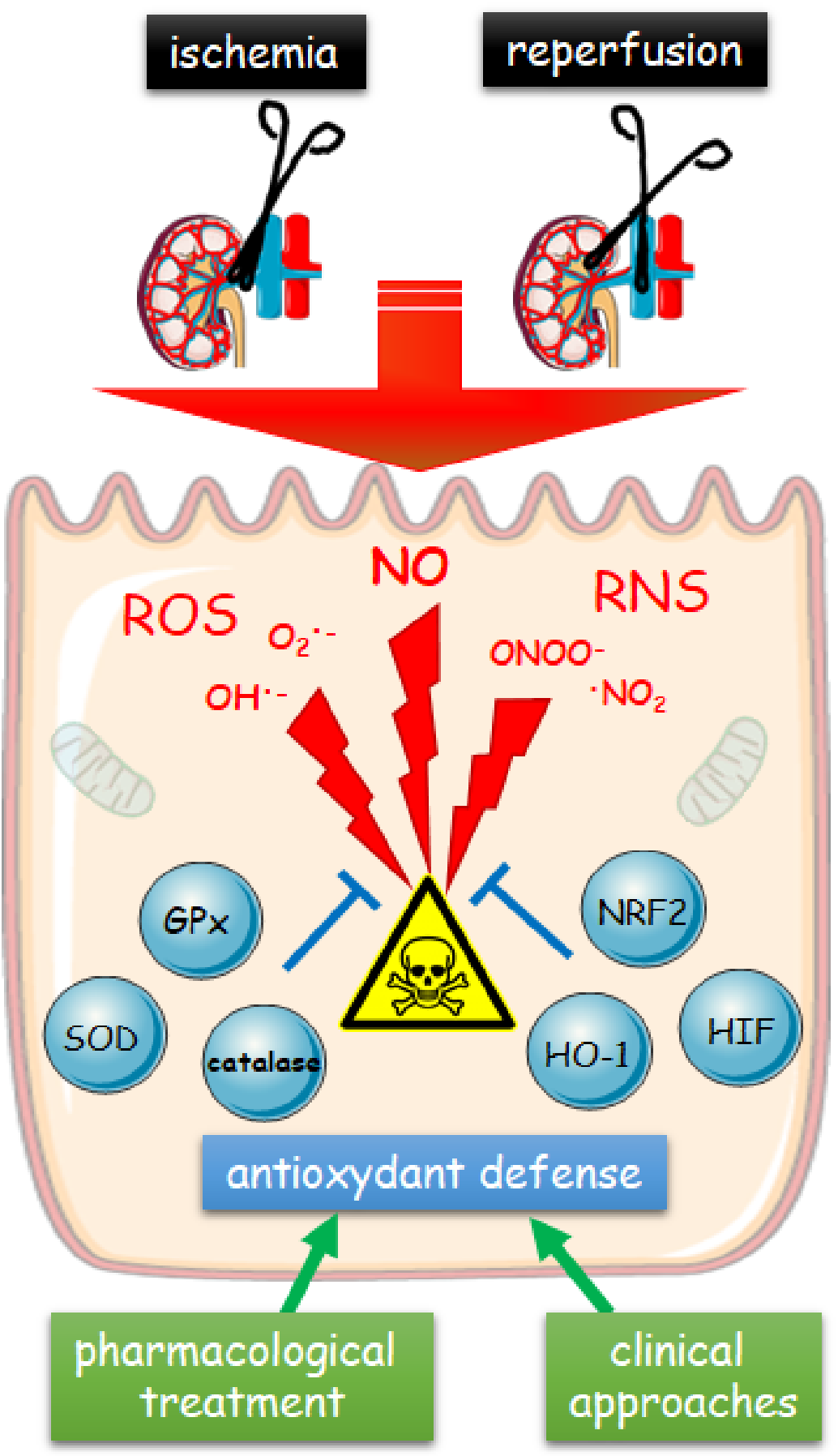


The phenomenon of ischemia/reperfusion $(I / R)$ is characterized by a blood supply arrest to a specific tissue or organ. This leads first to oxygen deprivation, additionally to nutrients and glucose deprivation, and second to sudden hyperoxygenation inducing cell death through complex mechanisms and in fine to irremediable ischemic lesions $(1,2)$. This ischemic stress occurs in pathological situations such as impairments of the circulatory system (mainly stroke and myocardial infarction), but also during surgery involving arterial clamping such as in organ transplantation or in general- and cardiovascular surgeries (1). Reactive oxygen and nitrogen species (ROS and RNS), a major hazard in the absence of effective selfregulation, are excessively generated after $\mathrm{I} / \mathrm{R}$. They cause rapid injury of the tissues and contribute to damage expansion by stimulating inflammatory response. Ischemic injuries are one of the main challenges in public health. Their consequences are often a source of permanent deterioration for the well-being of patients. They are at the origin of acute kidney injury (AKI), increase the risk of delayed graft function (DGF), prime the donor kidney for rejection, and contribute to the long-term risk of graft loss. Unfortunately, and up to now, no clinical or pharmacological opportunity is truly effective against ischemic damage.

After transplantation, the functional recovery of the organ is better if the donor is alive, young and healthy (3). This is mainly because planning the surgery from a living donor allows shorter ischemia times and thereby better preservation of organ quality (4). The current increasing number of situations requiring transplantation has contributed to a shortage of organs and therefore necessitates an expansion of the number of potential donors $(5,6)$. It is therefore necessary to develop approaches to limit ischemic lesions in all types of donors, particularly brain dead and extended criteria or donation after circulatory death donors, in order to increase the quantity of transplantable organs and the quality of their functional recovery (5).

Thus, effective treatments to limit the morbidity and mortality of these ischemic lesions are in demand. The main reason of the lack of therapeutic approach is the absence of clearly identified pharmacological targets, among numerous candidates, probably because the consequences of an ischemic stress are diverse and involve many physiological pathways. An emerging field demonstrates the role of oxidative stress in I/R (7) and more particularly the overproduction of ROS and RNS that 
indistinctly react with local proteins, lipids or nucleotides. More and more studies are focused on their roles in current clinical and pharmacological treatments, and new approaches and molecules emerged as potentially efficient to limit or blunt $\mathrm{I} / \mathrm{R}$ deleterious consequences (8). In this review, we will described ROS and RNS origin (Figure 1 ) and effect along $\mathrm{I} / \mathrm{R}$ by focusing on kidney transplantation, finally we will present several new interesting approaches developed in preclinical models to limit ROS and RNS impact at various step of kidney transplantation protocols.

\section{Oxidative species production along kidney $\mathrm{I} / \mathrm{R}$.}

The context of kidney transplantation is particular as kidney consumes $10 \%$ of the body's total oxygen and is therefore extremely sensitive to I/R (9). This sensitivity is also explained by the fact that the oxygen level supplied to the renal parenchyma is relatively low due to oxygen shunt diffusion between the arterial and venous vessels, which are close to each other in the kidney (10). Indeed, the partial pressure of oxygen is higher in the renal vein than at any site in the cortex, which implies precapillary oxygen shunting from the arteries to the veins (11). Consequently, microvascular oxygen pressure in the kidney decreases faster compared to other organs when systemic blood oxygen supply decreases as found during anaemia or blood flow arrest (12). This leads the kidney more rapidly to hypoxia condition. Conversely, this preglomerular arterial-venous shunt protects partially the kidney during reperfusion by limiting the fast rise in oxygen pressure (13). In kidney transplantation, ischemic damages are initially produced when the kidney perfusion and blood flow are temporarily stopped, called warm ischemia step (Figure 2). When the availability of oxygen falls below a critical value, the aerobic energy source is compromised, i.e. the rate at which adenosine triphosphate (ATP) is generated falls below the rate of its use by the cell (1). This lack of oxygen triggers anaerobic metabolism and disrupts the synthesis of aerobic ATP, leading to generation of oxidative stress (14). In addition, lesions also appear upon recovery from reperfusion, where the return of oxygen overwhelms the cell capacity and generate oxidative stress (Figure 2) (7). This I/R phenomenon therefore generates an oxidative stress sequence characterized by an overproduction, in duration and quantity, of ROS and other oxidative species as RNS (Figure 1 and 2) (15). 


\subsection{Generalities about ROS and production pathways}

The reduction of $\mathrm{O}_{2}$ to $\mathrm{H}_{2} \mathrm{O}$ is characterized by a series of redox reactions (transfer of electrons to the final acceptor) giving rise to several reduced intermediates which are called primary radicals such as the superoxide anion $\left(\mathrm{O}_{2}{ }^{\circ}\right)$, the hydroxyl radical $\left(\mathrm{OH}^{*}\right)$ as well as non-radical oxygenated derivatives such as hydrogen peroxide $\left(\mathrm{H}_{2} \mathrm{O}_{2}\right)$ (Figure 1). These free radicals or oxygen derivatives, generally termed ROS, carry a single electron on their outer shell, making them unstable and so able to (highly) react with other surrounding chemical molecules (16). Essential for cell signalling and sensors of environmental changes $(16,17)$, ROS are present in the cells at physiological concentrations due to an equilibrated balance between their production and their elimination via antioxidant systems (Figure 1) (18). A first way to regulate their concentration is to inhibit their production by sequestering transition metals, such as Iron $(\mathrm{Fe})$ and Copper $(\mathrm{Cu})$, which can react with $\mathrm{H}_{2} \mathrm{O}_{2}$ and generate $\mathrm{OH}^{*}$ (= Fenton reaction). A second method makes it possible to metabolize these ROS via enzymes. While mitochondrial (Mn-SOD) and cytoplasmic (Cu/Zn-SOD) superoxide dismutase catalyse the transformation of $\mathrm{O}_{2} \cdots$ in $\mathrm{H}_{2} \mathrm{O}_{2}$, catalase and glutathione peroxidase (GPx) generate $\mathrm{H}_{2} \mathrm{O}$ from $\mathrm{H}_{2} \mathrm{O}_{2}$ (18).

Most of the ROS are produced by the mitochondria, but they also come from other cellular sources (Figure 1) (16). The balance between production and detoxification can be upset either by an overproduction of ROS (as in cases of aging, atherosclerosis or cancer) or by a decrease in antioxidant capacity (as in obese or smokers where they are already used). The deficiency of these protective systems leads to oxidative stress causing irreversible oxidation of biological molecules such as DNA and proteins, and ultimately cell death by apoptosis (19). Among the numerous and complex cellular and molecular mechanisms involved in $\mathrm{I} / \mathrm{R}$, mitochondria play a key role (20). Impairment of mitochondrial function and loss of energy metabolites are particularly important. The depletion in oxygen supply during ischemia affects directly the mitochondrial coupling, causing inhibition of electron transport in the mitochondrial respiratory chain and decrease in ATP levels $(15,19)$. This condition leads to an impairment of the $\mathrm{Na}^{+} / \mathrm{K}^{+}$pump, membrane depolarization and intracellular $\mathrm{Ca}^{2+}$ accumulation: a typical scenario that links the mitochondrial respiratory activity and the mechanism of $\mathrm{I} / \mathrm{R}$ injury. Mitochondrial alteration associated with the accumulation of 
$\mathrm{Ca}^{2+}$ and the production of free radicals triggers apoptosis with an increase in membrane permeability (opening of the mitochondrial transition pore MTP), the release of cytochrome $C$ and mainly activation of caspase 9 and then other apoptotic proteases $(2,21)$.

\subsection{Mitochondrial ROS production during $\mathrm{I} / \mathrm{R}$}

The synthesis of aerobic ATP, or oxidative phosphorylation (OXPHOS), is carried out at the level of the mitochondrial inner membrane via electron transport chains composed of 5 complexes (I to $\mathrm{V}$ ), electron transporters such as ubiquinone (coenzyme $\mathrm{Q}(\mathrm{CoQ})$ ) and cytochrome c (Cyt c). This allows a flow of electrons from complex I to complex IV, which is coupled with the formation of a proton gradient between the inter-membrane space and the matrix of the mitochondria, thus conveying the energy necessary for the synthesis of ATP at the level of the complex V (ATPsynthase) (22). Physiologically, during these transfer reactions, 1 to $5 \%$ of the electrons escape and result in the production of ROS which are eliminated by the cell detoxification systems $(22,23)$. During ischemia complexes I and III functions are altered, leading to the generation of ROS (Figure 1) (24-26). This production seems to be linked to the membrane potential and/or to the redox state of the substrate. More precisely, the production of superoxide anions by complex I is optimized by a high $\mathrm{NADH} / \mathrm{NAD}^{+}$ratio and/or a high membrane potential. An elevated potential promotes the reduction of electron carriers and increases their movement into the complex. If the electron carriers are reduced, the production of superoxide anion $\mathrm{O}_{2}{ }^{*-}$ increases (27).

At the level of complex III, the oxidation/reduction cycles of quinones generate unstable semiquinone intermediates that move freely in the complex allowing the electron escape towards $\mathrm{O}_{2}$, thus forming ROS (28). During reperfusion, the reactivation of aerobic metabolism and hyperoxygenation also alters the functioning of mitochondrial complexes, inducing an increase in the production of ROS, which exceeds the antioxidant capacity of the cell (29). 


\subsection{Non-mitochondrial ROS production along I/R.}

\section{a) Xanthine oxidase}

Xanthine oxidoreductase (XOR) is an enzyme that exists in two forms; xanthine dehydrogenase $(\mathrm{XDH})$ and xanthine oxidase $(\mathrm{XO})$ which respectively use $\mathrm{NAD}^{+}$and $\mathrm{O}_{2}$ as electron acceptors (Figure 1). Thus, $\mathrm{XDH}$ generates NADH concomitantly to the oxidation of hypoxanthine in xanthine, which is in turn oxidized in uric acid by XO concomitantly to the production of $\mathrm{O}_{2}{ }^{\circ-}$. During $\mathrm{l} / \mathrm{R}$, an ischemic injury leads to a decrease in the energy load of the cell as well as a conversion of $X D H$ to $X O$. During reperfusion, oxygen reacts with XO leading to an overproduction of ROS (30).

\section{b) NAPDH oxidase}

The NADPH oxidase (NOX) family is made up of several enzymes (NOX$1,2,3,4,5$ and DUOX-1,2 for dual oxidase) capable of transporting electrons across the plasma membrane. It is involved in the production of extracellular ROS following I/R. DUOX and NOX enzymes produce extracellular superoxide radicals by reduction of one electron of oxygen using cytoplasmic NADPH as an electron donor (Figure 1) (31). $\mathrm{O}_{2}{ }^{*-}$ can generate spontaneously $\mathrm{H}_{2} \mathrm{O}_{2}$ which will serve as substrate of the peroxidase domain of DUOX enzymes to carry out other substrate oxidations. The kidney expresses preferentially NOX-1, -2 and -4 following a regional repartition along the nephron (32). While NOX-2 produces high level of $\mathrm{O}_{2} \cdot$ especially for pathogen response, other NOXs produce lower amounts of ROS as regulatory metabolites. In the kidney, NOXs are involved in various key function especially in glucose and electrolytes sensing and reabsorption (33).

Involvement of NOX subtypes in the oxidative stress due to $\mathrm{I} / \mathrm{R}$ is unclear. While NOX-2 knock-down protects mice from I/R injury (34), NOX-4 is required to limit fibrosis along chronic renal injury (35). Moreover, as NOXs activity is dependent both on oxygen and NADPH, which come from metabolization of glucose through the pentose phosphate pathway, their involvement at the ischemic stage where oxygen and glucose are unavailable is limited but increased with reperfusion. In addition, during ischemia and at the time of reperfusion, different chemical mediators with the potential to activate NOX are produced and released by cells. This include the activation of the 
complement system (36), the production of several cytokines as well as angiotensin II increase the activity of NADPH oxidase in post-ischemic tissues (37).

\section{c) Nitric oxide synthase uncoupling}

In addition to NO production (cf. §1.4), Endothelial nitric oxide synthase (eNOS) is directly involved in ROS generation (Figure 1). Indeed, in few conditions (tetrahydrobiopterin cofactor deficiency, NOS monomerization) NOS activity is altered and leads to an increase in $\mathrm{O}_{2}{ }^{--}$production instead of $\mathrm{NO}$ (38). This uncoupling of eNOS during I/R is involved in the generation of ROS and promotes damages to cell constituents (7).

\subsection{NO and RNS production during I/R.}

\section{a) NO and Nitric oxide synthase (NOS)}

All NOS isoforms generate nitric oxide (NO) by oxidation of L-arginine (Figure 1). The constitutive neuronal (nNOS/NOS1) and endothelial (eNOS/NOS3) isoforms of NOS generate low levels of intracellular NO involved especially in cGMP signal events. Differently, inducible NOS (iNOS/NOS2) can produce various quantity of NO, from low to high concentrations, correlating with various biological responses. eNOS and iNOS are highly expressed in kidney where they generate NO which is involved in various pathways depending on its production level (39). At low concentration NO can interact with iron and cupper generating metal nitrosyl complexes. This occurs especially with heme proteins, as cytochrome, haemoglobin, myoglobin and soluble guanyl cyclase, and can modify their activity. At higher concentration, NO acts mainly by S-nitrosative modification (= S-nitrosation or S-nitrosylation) of proteins, in general on the thiol group (SH) of cysteine residues. This modification leads to activation or inhibition of these proteins or to secondary modification as S-glutathyonilation (40).

Recently, it has been demonstrated that NO protects the kidney from I/R through S-nitrosation-mediated inhibition of a key protein of cell metabolism, pyruvate kinase M2 (PKM2) (41). In this work, S-nitrosation of PKM2 was obtained by the molecular inhibition of the denitrosylase AKR1A1, an enzyme which normally eliminates Snitrosation (42). PKM2, that belongs to the PK family composed of four isoforms 
(PKM1, PKM2, PKL and PKR), catalyses the final step of glycolysis to generate pyruvate from phosphoenolpyruvate (43). PKM2 has an increased interest in metabolic adaptation to hypoxia as it shunts the energy production generated by the Krebs's cycle from pyruvate in favour of lactate production via LDH $(44,45)$. Nevertheless, PKM2 inhibition by post-translational modifications as nitrosylation has also a high interest. Indeed, PKM2 inhibition leads to glycolysis block in its last step and promotes the accumulation of glycolytic metabolites which can be re-routed into the pentose phosphate pathway and thus generate the reducing factor $\mathrm{NADPH}$, required for the activity of antioxidant enzymes (46). These interesting results about the inhibition of PKM2 by NO, that have only been described in mouse genetic models for now, may open new perspectives in prevention of I/R injury. Indeed, pharmacological inhibitors of AKR1A1 (sulfonylnitromethane) and of PKM2 (shikonin, compound $3 K$ ) are already available and could be tested in pre-clinical models of I/R.

\section{b) Peroxynitrite and Reactive nitrogen species}

Peroxynitrite ( $\left.\mathrm{ONOO}^{-}\right)$is obtained by the non-enzymatic but diffusion-controlled combination of $\mathrm{NO}$ and $\mathrm{O}_{2}{ }^{*-}$, a reaction particularly present in the reperfusion stage of I/R (Figure 1). The involvement of peroxynitrite in oxidative stress is complex. Its generation leads to 1) a decrease in $\mathrm{O}_{2}{ }^{*-}$ and $\mathrm{NO}$ concentrations that can be considered as an antioxidant and protective mechanism, 2) a decrease in NO availability, and can limit protein nitrosation involved in cell survival and resistance to $\mathrm{I} / \mathrm{R}$. Therefore, peroxynitrite is considered at the same time as an oxidative compound and a precursor of several highly reactive species as carbonate $\left(\mathrm{CO}_{3}{ }^{*}\right)$ and nitrogen dioxide $\left({ }^{\circ} \mathrm{NO}_{2}\right)$ radicals.

Peroxynitrite can directly interact with the transition metal centres of proteins to inhibit their activity, as shown for heme containing proteins Cytochrome C (47) and iNOS (48) or non-heme proteins Aconitase (49) and eNOS (50). In addition, peroxynitrite can directly modify cysteine by thiol oxidation, such as in several glycolytic (51) and mitochondrial (52) key proteins, which demonstrated the crucial role of peroxynitrite in cell metabolism control. Due to the capacity of peroxynitrite to oxidize low-molecular-weight thiols as GSH, it can be scavenged by this antioxidant molecule and its toxic impact is highly related to intracellular GSH concentration (53). 
Through generation of ${ }^{-} \mathrm{NO}_{2}$, peroxynitrite can initiate lipid peroxidation as well as can modify tyrosine residues of proteins by addition of a nitrate residue. Tyrosine nitration is the main cytotoxic action of peroxynitrite and only targets a specific set of proteins (54), like Mn-SOD whose inhibition by tyrosine nitration in kidney transplantation leads to oxidative stress (55).

\subsection{Interrelation between ROS, NO and antioxidant pathways}

\section{a) The HIF pathway}

A family of hypoxia-inducible transcription factors (HIF) has been identified as mediators of transcriptional responses to hypoxia, which include the regulation of erythropoietin, metabolic adaptation, vascular tone, and neo-angiogenesis (56). This factor is composed of two subunits, an oxygen-sensitive HIF- $\alpha$ subunit and a constitutively expressed HIF- $\beta$ subunit, also named aryl hydrocarbon receptor nuclear translocator (ARNT) (57). Under normoxia the $\alpha$ subunit is hydroxylated by oxygenand iron- dependent prolyl hydroxylases (PHD) (Figure 1). This hydroxylation leads to HIF- $\alpha$ ubiquitination and degradation by the proteasome through the von HippelLindau-E3 ubiquitin ligase complex. Under low $\mathrm{O}_{2}$ levels, $\mathrm{PHD}$ is inactivated and prolyl hydroxylation is suppressed. Consequently, HIF- $\alpha$ subunits are stabilized, translocated to the nucleus and dimerized with their respective $\beta$ subunits, allowing nuclear expression of gene products by binding to hypoxia response elements (HREs), which are consensus sequences present in the gene regulatory regions (56). Three isoforms

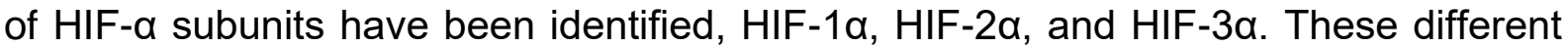
HIF- $\alpha$ subunits are known with variable tissue expressions and abundances but similar $\mathrm{O}_{2}$-dependent mechanisms of regulation: HIF-1 $\alpha$ is expressed in all nucleated cells and is responsible for acute responses; HIF-2a, which is expressed in the brain tissue, vascular endothelium, and type II pneumocytes, is responsible for chronic responses; and HIF-3a, is found in different area of the brain, lung, heart, liver, and kidney (58). HIF pathways regulate either specific or identical target genes, but all are involved in cell survival and metabolic adaptation under hypoxia $(59,60)$.

As HIF pathway is activated by hypoxia and mediates metabolic adaptation and survival of cells and organs, it plays a key role in I/R response and adaptation of kidney (61-63). In this organ, even if HIF-1 and HIF-2 pathway are involved in tissue 
adaptation to I/R, HIF-2 is mainly involved in interstitial and endothelial cells response while HIF-1 have a preponderant role in epithelial cells $(64,65)$. During prolonged activation, these isoforms exert mutually antagonistic effects on the redox state and on proinflammatory pathways (66). Consequently, persistent ischemia in renal tissues is a crucial factor in the development and progression of chronic kidney disease related to renal microcirculation rarefaction and vascular remodeling $(67,68)$. The main metabolic role of HIF pathways is to redirect pyruvate from oxidative phosphorylation to lactate production allowing a shift of the cell from aerobic to anaerobic metabolism. This role of HIF is in part mediated by the expression of PKM2 isoform of PK, instead of PKM1, the former favoring LDH metabolization of pyruvate and the latter pyruvate enter in Krebs's cycle (44).

HIF activity is of paramount importance in oxidative stress production and redox homeostasis and its relationship with ROS, NO and RNS is currently the subject of many studies (69). HIF can be regulated by ROS and NO production (70-72) and can reciprocally regulate, indirectly via cell metabolism or directly by modulating enzymes expression and activity, ROS and NO production $(73,74)$. An interesting target of HIF is heme oxygenase-1 enzyme (HO-1) $(75,76)$ which is involved in free heme catabolism leading to reduced heme-dependent ROS production. In addition, HO-1 degrades heme into biliverdin that is subsequently reduced to bilirubin (77), a major antioxidant molecule efficiently scavenging RNS (78).

In normoxic condition, NO is able to inhibit PHD by nitrosylation leading to HIF a subunit stabilization and thus its activity (Figure 1) (79). Differently, in hypoxic condition NO displays an opposite effect (Figure 1) (80). Several studies demonstrated that high concentrations of $\mathrm{NO}$ can inhibit mitochondrial activity, in part by Cytochrome C nitrosation, allowing reduced ROS production and/or redistribution of cellular $\mathrm{O}_{2}$, which leads to PHD activation and finally HIF-a degradation (81, 82). Others showed that $\mathrm{NO}$ can target directly the PHD targeting domain of HIF- $\alpha$ (83). Evidences showed that exogenous $\mathrm{H}_{2} \mathrm{O}_{2}$ addition, as well as $\mathrm{SOD}$ inhibition, is sufficient to stabilize HIFa protein in normoxic condition (Figure 1) $(84,85)$. Importantly, mitochondrial ROS production seems essential to activate HIF pathway under hypoxia and independently of OXPHOS activity (86-88). This modulation of HIF by ROS could be direct through oxidation of the iron co-factor of the PHD enzyme (89), or indirect through the decrease 
in NO concentrations due to ROS concentration increase leading to HIF-a stabilization (90).

\section{b) The NRF2/KEAP1 pathway}

The Nuclear factor erythroid2-related factor2 (NRF2), a master regulator of redox homoeostasis, is a key transcription factor binding to antioxidant responsive elements (AREs) and thus regulates a wide array of genes involved in the oxidative homeostasis of the cell. These target genes comprise glutathione s-transferases, enzymes involved in NADPH production and heme metabolism, such as HO-1 (91). This suggests a protective effect for a variety of organs from various kind of stress. The current knowledge on NRF2 regulation includes Kelch-like $\mathrm{ECH}$-associated protein 1 (KEAP1)-dependent and KEAP1-independent cascades (92, 93). The KEAP1/NRF2 system is a master regulator of cellular response against a variety of environmental stresses. NRF2 is constitutively synthesized but degraded by the NRF2specific ubiquitin ligase complex, in which Keap1 directly captures NRF2. KEAP1 contains cysteine thiols and acts as a sensor of ROS, NO and RNS produced during oxidative stress. Cysteine-modified Keap1 no longer binds to NRF2 which can also play its transcriptional factor function allowing a rapid and inducible response to redox insults (93).

NRF2 is activated in kidneys during $\mathrm{l} / \mathrm{R}$, mainly at the reperfusion step, but its activation seems not sufficient to protect efficiently the tissue to $I / R$ injury (94). Furthermore, NRF2 genetic inactivation decreased expression of antioxidant genes and aggravated kidney injury due to ischemia $(95,96)$, while genetic deletion of KEAP1 led to an hyperactivation of NRF2 and to an increased protection of kidney against I/R injury (94).

2. Which treatments are worth considering for preventing oxidative stress in organ transplant?

Transplantation requires an unavoidable $\mathrm{I} / \mathrm{R}$ sequence associated to deleterious effects at the cellular and tissue level (see above). As organ harvesting is the first step in transplantation, the donor status will therefore have an influence on the $\mathrm{I} / \mathrm{R}$ lesions. In a context of increasing organ demand, clinicians are required to use those from 
extended-criteria and circulatory death donors, two situations that maximize I/R injuries $(5,6)$ that could benefit from preconditioning treatments. While several clinical and pharmacological approaches have been developed in preclinical model to treat or prevent ischemic damage in the kidney, only a few are used in humans (8). We will discuss several therapies implemented in the donor and the recipient before, during and after transplantation to increase the tolerance of the kidney to I/R and to preserve their integrity (Figure 2).

\subsection{Clinical approaches}

The clinical protocols set up in donors involve warm ischemia, i.e. the graft is no longer perfused due to cardiac arrest or clamping of the artery irrigating it and this lasts until anastomosis (the reconnection of the graft's blood vessels to those of the recipient). The consequences of this interruption that are often irreversible are directly linked to the duration of blood low-flow and no-flow. To counter this issue, several types of protocols have been developed, first to preserve the graft and then to ameliorate its resistance to $\mathrm{I} / \mathrm{R}$ (Figure 2 ).

\section{a) Normothermic regional perfusion}

When the graft comes from alive or brain-dead donors the duration of warm ischemia can be planned and reduced, which is often not the case when the graft come from circulatory death donors. In this situation newly accepted in transplantation and to limit deleterious consequences, warm ischemia must be as short as possible $(<120$ 150 minutes) and after the 5 minutes of no-flow, a normothermic $\left(36.5-37.5{ }^{\circ} \mathrm{C}\right)$ regional perfusion allowing reoxygenation of the organs must be established $(97,98)$. The purpose of this normothermic regional perfusion is to extract the blood, oxygenate it through a membrane oxygenator allowing gas exchange similarly to alveolar situation, to maintain its temperature and then to inject it back through continuous or pulsatile perfusion. Conventionally, blood is taken with a cannula introduced into the femoral vein and reinjected through a second cannula introduced into the femoral artery. An intra-aortic occlusion balloon prevents the revascularization of the supraceliac region to limit the perfusion to the abdominal region (99). The objective of this technique is to optimize the oxygenation of the organ and therefore to limit the lesions due to warm ischemia as demonstrated in porcine preclinical model (100). This allows 
a better recovery of the grafts by improving renal blood flow and improving function during the early phase of reperfusion (97-99). One of the potential mechanisms for this improvement could be an early increase in circulating NO within the first hour of perfusion and a decrease in oxidative stress molecules (100).

\section{b) Donor and graft hypothermia}

An approach to limit warm ischemia and to prepare the graft to anoxia is the use of hypothermia, which reduces the oxygen requirements of the cells by $85-90 \%$ at $4-6^{\circ} \mathrm{C}$ and prevent destruction of cell structural elements. Hypothermia can be applied before graft harvesting by submitting donor to cold environment, especially for brain death donors. A comparison between mild hypothermic $\left(34-35^{\circ} \mathrm{C}\right)$ and normothermic $\left(36.5-37.5^{\circ} \mathrm{C}\right)$ preservation of brain-dead donors have demonstrated a significant reduced risk of delayed graft recovery function among recipients, especially for grafts from donors with comorbidities (101).

More commonly and independently of donor origin, graft is preserved ex situ from warm ischemia, until anastomosis into the recipient, by submitting it to cold following two different protocols: static cold ischemia or hypothermic ex situ perfusion. The advantages of one protocol compared to the others is still matter of debate (98, 102). Nonetheless, the graft is placed/perfused in/with cold preservation solution (4$\left.8^{\circ} \mathrm{C}\right)(103)$. In the case of hypothermic ex situ perfusion, the organ is connected to a perfusion machine. Several are available, but their vantages, in terms of ability to predict the functional quality of grafts based on perfusion parameters, remain to be demonstrated. However, randomized studies have shown that graft perfusion improves delayed function recovery in recipients, including grafts from uncontrolled donors $(104,105)$, and allows better kidney survival at 1 year (104). Recently, it was demonstrated using a porcine model, that non-oxygenated hypothermic ex situ perfusion allowed NO-dependent vasodilation of renal arteries as well as improved microcirculation of the renal cortex during reperfusion in recipient (106). Nevertheless, the biological processes associated with perfusion machine and allowing the reduction of lesions are not yet fully understood.

Many cold solutions have been developed and compared with the same objective of acting on the formation of free radicals and the occurrence of mitochondrial alterations. If interesting results have been obtained in pig preclinical models, no 
solution of conservation has so far proven to be of great superiority in terms of prevention of renal ischemia reperfusion in human and the use of different preservative liquids remains to the appreciation of each transplant team. Interestingly, molecules can be added to the preservation solutions to ameliorate graft outcome. Several of them are the focus of pre-clinical or clinical studies, such as extracellular haemoglobin (HEMO2 life and Hemarina-M101) developed from the marine worm Arenicola marina, that displays high $\mathrm{O}_{2}$ carrier capacity. After interesting results in pigs $(107,108)$, a study is ongoing in clinical setting (Clinical Trial NCT04181710).

This ex vivo preservation step is used in all transplantation protocols but is not enough to completely protect the graft from the I/R stress. More trickily, cold ischemia has been related to noxious effect leading to delayed function and graft failure risks. This seems related to the time of cold ischemia and can be partly prevented by reducing delay before transplantation (109). In addition, studies of deep mammalian hibernators, which naturally display reduction of metabolic rate and body temperature, have highlighted hydrogen sulfide $\left(\mathrm{H}_{2} \mathrm{~S}\right)$ as a key protector of cold induced renal injury (110). $\mathrm{H}_{2} \mathrm{~S}$ is an endogenously produced gaseous molecule with several cellular roles (111). Interestingly, $\mathrm{H}_{2} \mathrm{~S}$ is an antioxidant agent able to decrease mitochondrial metabolism and to increase intracellular GSH synthesis (111). $\mathrm{H}_{2} \mathrm{~S}$ exhibits promising protective effects in a variety of physiological and pathological processes and it have been extensively studied in the context of kidney disease and I/R (112). Interestingly, in models of rat kidney transplantation, $\mathrm{H}_{2} \mathrm{~S}$ supplementation of solution during graft cold ischemia preservation improved early graft survival and function and decreased kidney injury but did not modify graft rejection $(113,114)$. The encouraging results and increasing literature about $\mathrm{H}_{2} \mathrm{~S}$ make it promising to mitigate the inevitable cold injury during transplantation. In this way, various compounds allowing $\mathrm{H}_{2} \mathrm{~S}$ release, mainly after ROS or RNS activation, are under development and should open new perspectives in clinical use of $\mathrm{H}_{2} \mathrm{~S}$ in combination with cold ischemia (115).

\section{c) Ischemic preconditioning (IPC)}

In recent decades, ischemic preconditioning (IPC) or hypoxic conditioning have emerged as interesting opportunities for improving the success of organ transplant (116), because they could be used on the donor, the recipient or on the isolated organ, thus making it possible to prepare the organ for both future ischemic stress and to a 
lesser extent reoxygenation. IPC consists in applying brief repeated occlusion of the organ artery by clamping in order to mimic sequential ischemia and reperfusion steps. IPC induces protection against future and prolonged occlusion. So after a period of time (ranging from few minutes to several weeks before ischemia), tissue and organ develop resistance or tolerance to noxious stimuli, helping to prevent or reduce the damage that occurs in the future against the same kind of stress (117).

Effective protection of several IPC protocols has been described for kidney transplantation. i) Remote IPC that consists to multiple cycles of ischemia and reperfusion of leg or arm lower extremities allows protection of distant organs as kidney. This IPC protocol seems to trigger the release of circulating factors able to modulate kidney cells redox status and inflammation in response to ischemia (118). ii) Local IPC which involves the application of brief repeated clamping of the renal artery (119). This protocol directly stimulates the organ to activate signaling pathways, various genes transcription and associated enzyme activities which in turn modulate redox status and energetic metabolism to protect against ischemic injury (117). Unfortunately, these processes are long, invasive and the promising results described in animal models (119-121) have not been fully validated along human clinical trials (4, 122). Nevertheless, encouraging results have been obtained in REPAIR clinical trial that showed evidence of remote IPC benefits on the glomerular filtration rate after kidney transplantation $(123,124)$. Numerous studies aimed to characterize the signaling pathways and molecular mechanisms induced by IPC to develop better pharmacological approaches. Moreover, as IPC protocols need to be anticipated, it would be of high interest to develop pharmacological approaches reducing this preconditioning delay (125). These holds promise to increase both the number of potential grafts and the resumption of function of these grafts, the two limiting factors to date in renal transplantation.

\section{d) Ozone oxidative preconditioning (OzoneOP)}

Ozone, an allotropic gaseous variety of oxygen, heavier than air and very toxic at high concentration, has been used as a therapeutic agent in Human $(126,127)$ due to its anti-oxidant properties (128). Preconditioning of rats by a daily insufflation of ozone, through a rectal route and for a period of 15 days, provide organ protection in renal and hepatic I/R injury $(129,130)$. This phenomenon is called ozone oxidative 
preconditioning (OzoneOP). The amelioration of rat kidney function after $\mathrm{l} / \mathrm{R}$ by OzoneOP involve stimulation of antioxidant system, as GSH levels, GSH peroxidase and SOD expression, NO levels and both eNOS and iNOS expression (131). NO production seems crucial for OzoneOP effect, as pharmacological manipulation with the non-selective NOS blocker (L-NAME) abolishes its protective properties. Interestingly, OzoneOP displays the same effects that IPC (applied with the same frequency) and no additivity was found (131). These findings indicate that OzoneOP has important clinical implications, particularly to replace IPC in view of minimizing the invasively and simplifying the protocol of preconditioning before transplantation.

\subsection{Pharmacological approaches}

By studying oxidative stress and its repercussions in greater depth, several pharmacological molecules have been tested to reduce this stress, particularly by targeting ROS and NO production or by directly mimicking hypoxia (Figure 2).

\section{a) Activators of HIF pathway}

It has been demonstrated that IPC activates HIF-1 downstream pathway and participates to resistance of the organ against $\mathrm{I} / \mathrm{R}(64,132)$. Thus, multiple HIF activators have been experimented to protect kidney from I/R, mainly by inhibiting PHD using iron-chelator, iron-competitor or other PHD inhibitors, which lead to HIF- $\alpha$ stabilization.

Desferrioxamine (DFO) is an iron-chelator used to treat iron overload or $\beta$ thalassemia in Human, but it displayed inconsistent results when used alone, even exhibiting toxicity at high doses $(133,134)$. DFO, injected concomitantly to reperfusion, prevents $\mathrm{I} / \mathrm{R}$ induced injuries in different animal models $(135,136)$. Unfortunately, to date clinical translation of DFO and its derivatives failed in treatment of human kidney injury (137) and severe adverse effects have been found $(138,139)$. In the same way, Cobalt chloride $\left(\mathrm{CoCl}_{2}\right)$ is a recognized hypoxia-mimicking agent inhibiting PHD mostly by competition with iron i) within active site of PHD or ii) at the level of membrane transporter so limiting iron influx. $\mathrm{CoCl}_{2}$ displayed antioxidant and anti-inflammatory effect on renal cells in vitro (140) and protected kidney in vivo in a rodent renal I/R model when administrated from day 10 before injury up to day 3 after this one (141). 
$\mathrm{CoCl}_{2}$ has been used in clinic for some applications as anemia, but never in case of human kidney injury. Moreover, $\mathrm{CoCl}_{2}$ displayed known toxic effect at high doses (142).

FG-4497 is a PHD inhibitor which promotes renal ischemia tolerance in ex vivo rat models of $\mathrm{I} / \mathrm{R}$ in perfused kidneys (143) and in vivo following kidney transplant (144), when it is used 6 hours before intervention. This compound deserves consideration to be transposed in Human clinic, but to the best of our knowledge there is no running clinical trials addressing its effect. Differently, several pre-clinical data are available (145) and clinical trials are ongoing (146) for FG-4592 (Roxadustat) in the treatment of anemia and chronic kidney disease. This molecule structurally related to FG-4497 but chemically distinct prevents cisplatin-induced kidney injury in mouse (147) and might be tested in other pre-clinical kidney I/R injury and transplant models to clearly assess its potential. Unfortunately, no mechanistic analysis is available to explain renal protection by these compounds apart from their known effect on HIF activity.

\section{b) Activators of NRF2 pathway}

Several pharmacological activators of NRF2 are available and have been experimented in kidney injury models. Among them, 1-[2-cyano-3-,12-dioxooleana1,9(11)-dien-28-oyl]-imidazolide (CDDO-imidazolide) and CDDO-methyl ester, also named bardoxolone, are triterpenoids able to covalently bind to cysteine residues of KEAP1 and thus to inhibit its association with NRF2 (148). CDDO-imidazole daily treatment from 24 hours before to 24 hours after kidney ischemia protects efficiently the kidney to $I / R$ injury and alleviates mice survival. Differently, if the treatment is administrated once 1 day after ischemia, it does not protect mice against I/R injury (149). In another model of I/R in mice, oral administration of CDDO-imidazolide after reperfusion, and then every two days, ameliorates kidney function and limits tissue damages (150). This demonstrates that initiation of CDDO-imidazolide treatment at the reperfusion stage is essential to obtain a protection of the kidneys from I/R injury (150). These results are confirmed in a rat model of $\mathrm{I} / \mathrm{R}$ where pre-treatment few hours before injury with CDDO-methyl ester reduces early renal damage by reducing oxidative stress and increasing antioxidant defence (151). These studies demonstrate that CDDO derivatives have the potential to be used in clinic to reduce renal IR injury through antioxidant effects. CDDO-methyl ester has been already used in several 
clinical trials to treat chronic kidney disease in diabetic patients. A non-placebo controlled trial first (152) and then a double-blind and placebo-controlled trial demonstrate an increase in glomerular filtration rate (GFR) in patients treated with CDDO-methyl ester (153). Unfortunately, the phase 3 trial has been stopped early due to increased incidence of heart failure in patients treated with CDDO. Nevertheless, in this trial CDDO group displays also an increase in GFR (154). Taken together, these data suggest that pharmacological activation of NRF2 pathway can ameliorate kidney function in human, but the long-term impact on the tissue is still not evaluated and the adverse effect on heart function is challenging.

Instead of CDDO, other compounds are of interest such as sulforaphane, a natural isothiocyanate coming from the hydrolysation of the glucoraphanin present in cruciferous vegetables (155). Due to its ability to chemically modify the cysteine sensors of KEAP1, like CDDO, sulforaphane is a potent NRF2 activator (156). Sulforaphane inhibits renal injury in rats and preserves organ function when it is injected 24 hours (157) or just before I/R (158). This is related to an increased Nrf2 activity and antioxidant enzyme expression, concomitantly to a decreased Keap1 expression. Closer to human situation, it has been demonstrated using a kidney transplantation model in rats that sulforaphane improves post-transplant kidney function recovery and prevents tubular injury (159). Interestingly in this work, graft and donor were untreated as sulforaphane is injected only in recipient rats 24 and 1 hour before the surgery, and 6 hours after. 48 hours after transplant, kidney grafted in treated rats displayed an increase in antioxidant defence compared to those from untreated rats (159). Another very interesting study in rat analyses long term effect of sulforaphane in a chronic renal allograft dysfunction model. Transplanted rats were treated every day and followed for 24 weeks. Sulforaphane treated rats displayed kidney function improvement and delayed renal morphological deterioration. This protective effect was related to a decrease in oxidative marker due to activation of NRF2 (160). However, in this model the protective effects of sulforaphane is not apparent early after graft but needs to be sustained several weeks before to clearly perceive any protective effect (160). Altogether, these approaches demonstrated the efficiency of sulforaphane to protect kidney from oxidative stress as well as early after the reperfusion stage and later with an increased kidney function recovery. At this date, no clinical approaches have been developed using sulforaphane in a context of renal 
graft or kidney ischemic injury, but several trials targeting other diseases are ongoing (155).

In another way, an elegant study led in a pig model of kidney transplantation reported that the preconditioning of the donor with the spermidine analog N1-guanyl1,7-diamine-heptane (GC7) at the time of the brain death and during the 4 hours management period limits late graft dysfunction in part through the enhancement of the expression of NRF2 (161). These data open a new pharmacological approach concerning the stimulation of oxidative stress defences including NRF2. The other beneficial effects of GC7 in kidney transplantation will be exposed below.

\section{c) Anaesthetics}

In addition to their anaesthetic and analgesic effects, volatile anaesthetics, as isoflurane and sevoflurane, both used during and after renal ischemia protect rodent kidney against I/R injury (162-164). In the same way, propofol limits kidney I/R injury in rat $(165,166)$, and displays in human an equivalent $(167)$ or better renal protection compared to other volatile anaesthetics $(168,169)$ after a vascular surgery leading to kidney I/R injury. The exact mechanism induced by these anaesthetics are yet unknow. Nevertheless, this protective effect is linked to antioxidant and anti-inflammatory activities, especially for propofol as demonstrated in porcine model of kidney I/R (170). The same kind of results were found with xenon, an another anaesthetic gas, when it is used as preconditioning agent in mouse the day before $\mathrm{I} / \mathrm{R}(171)$, but at this date no clear results have been found in human (172).

\section{d) Inhibitors of ROS production}

To directly inhibit ROS production, several pharmacological compounds known to inhibit enzymes that produce ROS have been evaluated in preclinical model of kidney I/R. Among these, some interesting results have been found using pretreatment with the NOX inhibitors ML171 and apocynin $(173,174)$, or the XO inhibitors allopurinol $(174,175)$ and febuxostat both in pre- (176) or post-treatment (177). Allopurinol is an already used compound in human to treat gout and kidney stones and thus deserves consideration to prevent kidney injury due to I/R in clinic (178). 
a-bisabolol is an alcohol of the terpene family that inhibits NAPDH oxidase; NOX4. When used as post-treatment in a rat I/R injury a-bisabolol helps to attenuate ischemic damage (179). In addition, it has been shown in vitro that treatment with $\alpha$ bisabolol leads to an increase in cell viability as well as a decrease in the production of ROS. This was performed on LLC-MK2 monkey proximal tubular epithelial cells under anaerobic conditions as well as on immortalized proximal tubular epithelial cells from a normal adult human kidney HK2 under hypoxia. This molecule has antioxidant properties as well as the ability to restore the mitochondrial membrane potential, thus allowing an improvement in cellular respiration (180). These promising results need to be expanded in preclinical models.

The use of mimetics of the enzymes responsible for ROS metabolization also improves post I/R results. They allow the ROS to be trapped, thus having beneficial effects on the mitochondrial metabolism. TEMPOL is a SOD mimetic able to scavenge superoxide thereby to interfere at an early stage of the redox chain. In fact, the chelation of superoxide suppresses the production of $\mathrm{H}_{2} \mathrm{O}_{2}$ as well as the production of NO (181). TEMPOL therefore provides antioxidant protection and prevents ROS from reducing mitochondrial function during $\mathrm{I} / \mathrm{R}$. This compound when used throughout the period of $\mathrm{I} / \mathrm{R}$ in rats provides better, but partial, recovery of several parameters of renal function $(182,183)$.

\section{e) Inhibitors of RNS production}

Few compounds have been developed to directly inhibit NO production and its reactive metabolites, certainly due to the ambivalent role of $\mathrm{NO}$ in $\mathrm{l} / \mathrm{R}$ protection. In this way, it has been demonstrated in rat that inhibition of NO production worsens kidney injury after I/R differently to induced NO production which protects the kidney (184, 185). Nonetheless, a study showed that inhibition of iNOS, using S-methylisothiourea, 6 hours before kidney $\mathrm{l} / \mathrm{R}$ in rat partially prevents kidney injury and decreases oxidative stress (186). More importantly, in the same study, treatment 6 hours before $\mathrm{I} / \mathrm{R}$ with a scavenger of peroxynitrite (mercaptoethylquanidine) protected powerfully kidney from $\mathrm{I} / \mathrm{R}$ injury (186). These results seem to demonstrate that blockade the final reactive species generated from ROS and RNS is sufficient to protect kidney from oxidative stress. 


\section{f) Inhibitors of Ferroptosis}

Recently, a new form of regulatory cell death called Ferroptosis, with a highly iron- and ROS-dependence has been described (187). This particular cell death is usually accompanied by a large amount of iron accumulation and lipid peroxidation. Ferroptosis-inducing factors can directly or indirectly affect glutathione peroxidase through different pathways, resulting in a decrease in antioxidant capacity and accumulation of ROS in cells, ultimately leading to oxidative cell death. Indeed, it has been shown that ferroptosis could directly cause necrosis of renal tubules in models of I/R injury (187). Since a decade, in vitro studies have widely used the small molecule ferrostatin-1 (Fer-1), a potent and specific inhibitor of iron induced lipid peroxidation and thus of ferroptosis. However, despite the overwhelming evidence highlighting the therapeutic efficacy of Fer-1, the translation of Fer-1 in clinical application is limited due to its instability in vivo $(188,189)$.

Recently, new drugs have been used and developed and one of them is quercetin, a natural flavonoid. Flavonoids form a class of polyphenolic compounds (tannins in the broad sense) ubiquitous in vascular plants (including vegetables and cereals). An in vitro study has shown that quercetin inhibits ferroptosis in renal proximal tubular epithelial cells (190). Moreover, acute treatment with quercetin before $\mathrm{I} / \mathrm{R}$ prevented mouse kidney function and limited morphological alterations. In this model, quercetin reduced tubular necrosis, renal inflammation and increased the levels of antioxidant pathways and GSH (190). In addition to its effect on ferroptosis, a plausible explanation for the effects of quercetin is the induction of the antioxidant enzyme $\mathrm{HO}$ 1 (191). These results are encouraging and echo an older clinical study showing beneficial effects of quercetin and curcumin after renal transplantation (192). Indeed, post-surgery treatment of recipient patients for one month with quercetin and curcumin improved early graft function and no acute rejection was found up to six months compared to placebo population. To note, $\mathrm{HO}-1$ expression is increased in quercetin treated patients (192).

\section{g) Inhibitor of eIF5A hypusination}

A crucial link between hypoxic tolerance and inhibition of Eukaryotic Translation Initiation Factor 5A (elF5A) protein has recently been demonstrated (193). elF5A is 
activated by a post-translational modification, called hypusination, unique and extremely conserved mechanism in living organisms. This modification is carried out from the polyamine spermidine by the successive action of two enzymes: deoxyhypusine synthase (DHPS) and deoxyhypusine hydroxylase (DOHH) (Figure $3 A)$. The elF5A protein and its activated hypusinated form play an essential role in cell growth from yeast to eukaryotic cells (194).

It has been shown in an I/R rat model by temporary occlusion of the renal artery, that the inhibition of elF5A hypusination by GC7 (N1-guanyl-1,7-diamineoheptane), a spermidine analogue and specific DHPS inhibitor (195), protects renal function from the induced ischemic stress (196) (Figure 3B). These results have been transposed in a relevant preclinical model of kidney transplantation in pigs (161) (Figure 3C). In this model, the ischemia reperfusion alone induces early and late graft dysfunction (197), whereas pretreatment of the donor with GC7 improves drastically the functional recovery of the graft up to 3 months after the surgery, whether the donor is alive (196) or a brain death donor (161). This includes an effective diuresis one day posttransplantation in GC7-preconditioned group vs. 3 days in control group, as well as a protection against interstitial fibrosis 3 months post-transplantation in GC7preconditioned kidney $(161,196)$. It appears clearly that GC7 preconditioning improves graft function outcome in kidney transplantation.

The molecular mechanisms involved in GC7 protection that appeared to be concomitant but not directly related to HIF-1a stabilization have been studied in vitro on cells isolated from the proximal convoluted tubule (PCT) of mouse kidneys (Figure 3D). GC7 preconditioning drastically decreases mitochondrial oxidative phosphorylation process in PCT cells that almost exclusively performed anaerobic glycolysis (196). Consequently, PCT cells are able to survive in hypoxic and anoxic conditions for more than 24 hours and regain a completely normal metabolism after a 48 hours period of recovery $(196,198)$. Interestingly, while GC7-preconditioned cells produce less ROS under anoxic condition, this was not investigated whether it is a cause, or a consequence of the GC7-induced protection. Similar results have been found in vivo in brain-death pigs donors, where GC7 preconditioning decreases ROS production in the kidney of donor as well as RNS production characterized by a decrease in nitrosated tyrosine residue which are due to peroxynitrite (161). Thus, 
preconditioning of brain-death pig with GC7 reduces both the production and the impact of oxidative stress on GC7-preconditioned kidney, and ultimately ameliorates graft function recovery. To note, GC7 delivered as a pre- or post-treatment has also been shown to afford neuronal and brain protection against ischemic stroke (199). Indeed, GC7 is able to protect primary neurons submitted to an oxygen and glucose deprivation protocol and to limit infarct volume and post-stroke deficits in a mouse model of transient focal cerebral ischemia ( $\mathrm{tFCl}$ ). Interestingly, in these models the GC7-induced protection of mitochondria and reduction of oxidative stress was similar to those observed in kidney models (199). This suggests that the effect of GC7 is not specific to a cell type or organ but targets a deleterious mechanism specific to ischemia linked to oxidative stress.

\section{Conclusion and Perspectives}

Lesions due to both blood flow and oxygen arrest and recovery have been the focus of numerous basic and clinical researches in recent years. Various molecular mechanisms have been proposed to explain the impact of ischemia/reperfusion in different organs. During kidney $\mathrm{I} / \mathrm{R}$ the excessive production of ROS and RNS is considered to be among the major causes of injury (Figure 1). These reactive species that contribute to oxidative stress are produced at an accelerated rate in tissues subjected to $I / R$ and their accumulation contributes to reperfusion injury (Figure 2). Research has focused on the direct deleterious effects of ROS and RNS and the molecular aspects of cell dysfunction. Notable progress has been made in the comprehension of the contribution of the different sources of ROS and RNS production in tissues exposed to $\mathrm{I} / \mathrm{R}$. These studies provide a new perspective on the adaptation of cells and grafts to oxidative stress and have led to several pharmacological treatments to prevent ischemic lesions, especially during kidney transplant (Figure 2). As highlighted in this review, the use of a single treatment alone is not sufficient to prevent all $\mathrm{I} / \mathrm{R}$ damages, emphasizing the potential benefit of combining several approaches to reach optimal protection.

\section{Bibliographie}

1. Eltzschig HK, Eckle T. Ischemia and reperfusion--from mechanism to translation. Nat Med. 2011;17(11):1391-401. 
2. Lopez-Neblina F, Toledo AH, Toledo-Pereyra LH. Molecular biology of apoptosis in ischemia and reperfusion. J Invest Surg. 2005;18(6):335-50.

3. Saat TC, van den Akker EK, JN IJ, Dor FJ, de Bruin RW. Improving the outcome of kidney transplantation by ameliorating renal ischemia reperfusion injury: lost in translation? J Transl Med. 2016;14:20.

4. Veighey K, MacAllister R. Ischemic Conditioning in Kidney Transplantation. J Cardiovasc Pharmacol Ther. 2017;22(4):330-6.

5. Rosendale JD, Chabalewski FL, McBride MA, Garrity ER, Rosengard BR, Delmonico FL, et al. Increased transplanted organs from the use of a standardized donor management protocol. Am J Transplant. 2002;2(8):761-8.

6. Pessione F, Cohen S, Durand D, Hourmant M, Kessler M, Legendre C, et al. Multivariate analysis of donor risk factors for graft survival in kidney transplantation. Transplantation. 2003;75(3):361-7.

7. Granger DN, Kvietys PR. Reperfusion injury and reactive oxygen species: The evolution of a concept. Redox biology. 2015;6:524-51.

8. Melis N, Thuillier R, Steichen C, Giraud S, Sauvageon Y, Kaminski J, et al. Emerging therapeutic strategies for transplantation-induced acute kidney injury: protecting the organelles and the vascular bed. Expert Opin Ther Targets. 2019;23(6):495-509.

9. Hansell P, Welch WJ, Blantz RC, Palm F. Determinants of kidney oxygen consumption and their relationship to tissue oxygen tension in diabetes and hypertension. Clin Exp Pharmacol Physiol. 2013;40(2):123-37.

10. Honda T, Hirakawa $\mathrm{Y}$, Nangaku $\mathrm{M}$. The role of oxidative stress and hypoxia in renal disease. Kidney research and clinical practice. 2019;38(4):414-26.

11. Welch WJ, Baumgartl H, Lubbers D, Wilcox CS. Nephron pO2 and renal oxygen usage in the hypertensive rat kidney. Kidney Int. 2001;59(1):230-7.

12. van Bommel J, Siegemund M, Henny Ch P, Ince C. Heart, kidney, and intestine have different tolerances for anemia. Transl Res. 2008;151(2):110-7.

13. O'Connor PM, Anderson WP, Kett MM, Evans RG. Renal preglomerular arterialvenous $\mathrm{O} 2$ shunting is a structural anti-oxidant defence mechanism of the renal cortex. Clin Exp Pharmacol Physiol. 2006;33(7):637-41.

14. Raedschelders K, Ansley DM, Chen DD. The cellular and molecular origin of reactive oxygen species generation during myocardial ischemia and reperfusion. Pharmacol Ther. 2012;133(2):230-55.

15. Loor G, Kondapalli J, Iwase H, Chandel NS, Waypa GB, Guzy RD, et al. Mitochondrial oxidant stress triggers cell death in simulated ischemia-reperfusion. Biochim Biophys Acta. 2011;1813(7):1382-94. 
16. Schieber M, Chandel NS. ROS function in redox signaling and oxidative stress. Curr Biol. 2014;24(10):R453-62.

17. Forman $\mathrm{HJ}$, Maiorino M, Ursini F. Signaling functions of reactive oxygen species. Biochemistry. 2010;49(5):835-42.

18. Gutteridge JMC, Halliwell B. Mini-Review: Oxidative stress, redox stress or redox success? Biochem Biophys Res Commun. 2018;502(2):183-6.

19. Orrenius S, Gogvadze V, Zhivotovsky B. Mitochondrial oxidative stress: implications for cell death. Annu Rev Pharmacol Toxicol. 2007;47:143-83.

20. Mukhopadhyay P, Horvath B, Zsengeller Z, Batkai S, Cao Z, Kechrid M, et al. Mitochondrial reactive oxygen species generation triggers inflammatory response and tissue injury associated with hepatic ischemia-reperfusion: therapeutic potential of mitochondrially targeted antioxidants. Free Radic Biol Med. 2012;53(5):1123-38.

21. Jassem W, Fuggle SV, Rela M, Koo DD, Heaton ND. The role of mitochondria in ischemia/reperfusion injury. Transplantation. 2002;73(4):493-9.

22. Zhao RZ, Jiang S, Zhang L, Yu ZB. Mitochondrial electron transport chain, ROS generation and uncoupling (Review). Int J Mol Med. 2019;44(1):3-15.

23. Cadenas E, Davies KJ. Mitochondrial free radical generation, oxidative stress, and aging. Free Radic Biol Med. 2000;29(3-4):222-30.

24. Ricci JE, Gottlieb RA, Green DR. Caspase-mediated loss of mitochondrial function and generation of reactive oxygen species during apoptosis. J Cell Biol. 2003;160(1):65-75.

25. Ricci JE, Waterhouse N, Green DR. Mitochondrial functions during cell death, a complex (I-V) dilemma. Cell Death Differ. 2003;10(5):488-92.

26. Turrens JF. Mitochondrial formation of reactive oxygen species. J Physiol. 2003;552(Pt 2):335-44.

27. Chen Q, Vazquez EJ, Moghaddas S, Hoppel CL, Lesnefsky EJ. Production of reactive oxygen species by mitochondria: central role of complex III. J Biol Chem. 2003;278(38):36027-31.

28. St-Pierre J, Buckingham JA, Roebuck SJ, Brand MD. Topology of superoxide production from different sites in the mitochondrial electron transport chain. J Biol Chem. 2002;277(47):44784-90.

29. Chouchani ET, Pell VR, James AM, Work LM, Saeb-Parsy K, Frezza C, et al. A Unifying Mechanism for Mitochondrial Superoxide Production during IschemiaReperfusion Injury. Cell metabolism. 2016;23(2):254-63.

30. Lee MC, Velayutham M, Komatsu T, Hille R, Zweier JL. Measurement and characterization of superoxide generation from xanthine dehydrogenase: a redox- 
regulated pathway of radical generation in ischemic tissues. Biochemistry. 2014;53(41):6615-23.

31. Brandes RP, Weissmann N, Schroder K. NADPH oxidases in cardiovascular disease. Free Radic Biol Med. 2010;49(5):687-706.

32. Sedeek M, Nasrallah R, Touyz RM, Hebert RL. NADPH oxidases, reactive oxygen species, and the kidney: friend and foe. J Am Soc Nephrol. 2013;24(10):15128.

33. Nistala R, Whaley-Connell A, Sowers JR. Redox control of renal function and hypertension. Antioxid Redox Signal. 2008;10(12):2047-89.

34. Fukuda M, Nakamura T, Kataoka K, Nako H, Tokutomi $\mathrm{Y}$, Dong $\mathrm{YF}$, et al. Potentiation by candesartan of protective effects of pioglitazone against type 2 diabetic cardiovascular and renal complications in obese mice. J Hypertens. 2010;28(2):34052.

35. Sedeek M, Callera G, Montezano A, Gutsol A, Heitz F, Szyndralewiez C, et al. Critical role of Nox4-based NADPH oxidase in glucose-induced oxidative stress in the kidney: implications in type 2 diabetic nephropathy. Am J Physiol Renal Physiol. 2010;299(6):F1348-58.

36. Simone S, Rascio F, Castellano G, Divella C, Chieti A, Ditonno P, et al. Complement-dependent NADPH oxidase enzyme activation in renal ischemia/reperfusion injury. Free Radic Biol Med. 2014;74:263-73.

37. Barth BM, Stewart-Smeets S, Kuhn TB. Proinflammatory cytokines provoke oxidative damage to actin in neuronal cells mediated by Rac1 and NADPH oxidase. Mol Cell Neurosci. 2009;41(2):274-85.

38. Gebhart V, Reiss K, Kollau A, Mayer B, Gorren ACF. Site and mechanism of uncoupling of nitric-oxide synthase: Uncoupling by monomerization and other misconceptions. Nitric Oxide. 2019;89:14-21.

39. Thomas DD, Heinecke JL, Ridnour LA, Cheng RY, Kesarwala AH, Switzer CH, et al. Signaling and stress: The redox landscape in NOS2 biology. Free Radic Biol Med. 2015;87:204-25.

40. Mieyal JJ, Gallogly MM, Qanungo S, Sabens EA, Shelton MD. Molecular mechanisms and clinical implications of reversible protein S-glutathionylation. Antioxid Redox Signal. 2008;10(11):1941-88.

41. Zhou HL, Zhang R, Anand P, Stomberski CT, Qian Z, Hausladen A, et al. Metabolic reprogramming by the S-nitroso-CoA reductase system protects against kidney injury. Nature. 2019;565(7737):96-100.

42. Anand P, Hausladen A, Wang YJ, Zhang GF, Stomberski C, Brunengraber H, et al. Identification of S-nitroso-CoA reductases that regulate protein S-nitrosylation. Proc Natl Acad Sci U S A. 2014;111(52):18572-7. 
43. Israelsen WJ, Vander Heiden MG. Pyruvate kinase: Function, regulation and role in cancer. Semin Cell Dev Biol. 2015;43:43-51.

44. Williams AL, Khadka V, Tang M, Avelar A, Schunke KJ, Menor M, et al. HIF1 mediates a switch in pyruvate kinase isoforms after myocardial infarction. Physiological genomics. 2018;50(7):479-94.

45. Wu S, Le H. Dual roles of PKM2 in cancer metabolism. Acta biochimica et biophysica Sinica. 2013;45(1):27-35.

46. Puckett DL, Alquraishi M, Chowanadisai W, Bettaieb A. The Role of PKM2 in Metabolic Reprogramming: Insights into the Regulatory Roles of Non-Coding RNAs. Int J Mol Sci. 2021;22(3).

47. Thomson L, Trujillo M, Telleri R, Radi R. Kinetics of cytochrome c2+ oxidation by peroxynitrite: implications for superoxide measurements in nitric oxide-producing biological systems. Arch Biochem Biophys. 1995;319(2):491-7.

48. Huhmer AF, Nishida CR, Ortiz de Montellano PR, Schoneich C. Inactivation of the inducible nitric oxide synthase by peroxynitrite. Chem Res Toxicol. 1997;10(5):61826.

49. Castro L, Rodriguez M, Radi R. Aconitase is readily inactivated by peroxynitrite, but not by its precursor, nitric oxide. J Biol Chem. 1994;269(47):29409-15.

50. Zou MH, Cohen R, Ullrich V. Peroxynitrite and vascular endothelial dysfunction in diabetes mellitus. Endothelium. 2004;11(2):89-97.

51. Souza JM, Radi R. Glyceraldehyde-3-phosphate dehydrogenase inactivation by peroxynitrite. Arch Biochem Biophys. 1998;360(2):187-94.

52. Radi R, Cassina A, Hodara R. Nitric oxide and peroxynitrite interactions with mitochondria. Biol Chem. 2002;383(3-4):401-9.

53. Arteel GE, Briviba K, Sies $\mathrm{H}$. Protection against peroxynitrite. FEBS Lett. 1999;445(2-3):226-30.

54. Pacher P, Beckman JS, Liaudet L. Nitric oxide and peroxynitrite in health and disease. Physiol Rev. 2007;87(1):315-424.

55. MacMillan-Crow LA, Crow JP, Kerby JD, Beckman JS, Thompson JA. Nitration and inactivation of manganese superoxide dismutase in chronic rejection of human renal allografts. Proc Natl Acad Sci U S A. 1996;93(21):11853-8.

56. Semenza GL. Regulation of oxygen homeostasis by hypoxia-inducible factor 1 . Physiology. 2009;24:97-106.

57. Rabinowitz MH. Inhibition of hypoxia-inducible factor prolyl hydroxylase domain oxygen sensors: tricking the body into mounting orchestrated survival and repair responses. J Med Chem. 2013;56(23):9369-402. 
58. Gyongyosi A, Terraneo L, Bianciardi P, Tosaki A, Lekli I, Samaja M. The Impact of Moderate Chronic Hypoxia and Hyperoxia on the Level of Apoptotic and Autophagic Proteins in Myocardial Tissue. Oxid Med Cell Longev. 2018;2018:5786742.

59. Semenza GL. Regulation of cancer cell metabolism by hypoxia-inducible factor 1. Semin Cancer Biol. 2009;19(1):12-6.

60. Hu CJ, Wang LY, Chodosh LA, Keith B, Simon MC. Differential roles of hypoxiainducible factor 1alpha (HIF-1alpha) and HIF-2alpha in hypoxic gene regulation. Mol Cell Biol. 2003;23(24):9361-74.

61. Conde E, Alegre L, Blanco-Sanchez I, Saenz-Morales D, Aguado-Fraile E, Ponte B, et al. Hypoxia inducible factor 1-alpha (HIF-1 alpha) is induced during reperfusion after renal ischemia and is critical for proximal tubule cell survival. PLoS One. 2012;7(3):e33258.

62. Rosenberger C, Heyman SN, Rosen S, Shina A, Goldfarb M, Griethe W, et al. Up-regulation of HIF in experimental acute renal failure: evidence for a protective transcriptional response to hypoxia. Kidney Int. 2005;67(2):531-42.

63. Nangaku M, Inagi R, Miyata T, Fujita T. Hypoxia and hypoxia-inducible factor in renal disease. Nephron Experimental nephrology. 2008;110(1):e1-7.

64. Hill $P$, Shukla D, Tran MG, Aragones J, Cook HT, Carmeliet $P$, et al. Inhibition of hypoxia inducible factor hydroxylases protects against renal ischemia-reperfusion injury. J Am Soc Nephrol. 2008;19(1):39-46.

65. Rosenberger C, Griethe W, Gruber G, Wiesener M, Frei U, Bachmann S, et al. Cellular responses to hypoxia after renal segmental infarction. Kidney Int. 2003;64(3):874-86.

66. Packer M. Mutual Antagonism of Hypoxia-Inducible Factor Isoforms in Cardiac, Vascular, and Renal Disorders. JACC Basic to translational science. 2020;5(9):961-8.

67. Kerforne T, Favreau F, Khalifeh T, Maiga S, Allain G, Thierry A, et al. Hypercholesterolemia-induced increase in plasma oxidized LDL abrogated pro angiogenic response in kidney grafts. J Transl Med. 2019;17(1):26.

68. Maiga S, Allain G, Hauet T, Roumy J, Baulier E, Scepi M, et al. Renal autotransplantation promotes cortical microvascular network remodeling in a preclinical porcine model. PLoS One. 2017;12(7):e0181067.

69. Samanta D, Semenza GL. Maintenance of redox homeostasis by hypoxiainducible factors. Redox biology. 2017;13:331-5.

70. Mahfoudh-Boussaid A, Zaouali MA, Hadj-Ayed K, Miled AH, Saidane-Mosbahi $\mathrm{D}$, Rosello-Catafau J, et al. Ischemic preconditioning reduces endoplasmic reticulum stress and upregulates hypoxia inducible factor-1alpha in ischemic kidney: the role of nitric oxide. J Biomed Sci. 2012;19:7. 
71. Movafagh S, Crook S, Vo K. Regulation of hypoxia-inducible factor-1a by reactive oxygen species: new developments in an old debate. J Cell Biochem. 2015;116(5):696-703.

72. Selvaraju V, Parinandi NL, Adluri RS, Goldman JW, Hussain N, Sanchez JA, et al. Molecular mechanisms of action and therapeutic uses of pharmacological inhibitors of HIF-prolyl 4-hydroxylases for treatment of ischemic diseases. Antioxid Redox Signal. 2014;20(16):2631-65.

73. Chen R, Lai UH, Zhu L, Singh A, Ahmed M, Forsyth NR. Reactive Oxygen Species Formation in the Brain at Different Oxygen Levels: The Role of Hypoxia Inducible Factors. Frontiers in cell and developmental biology. 2018;6:132.

74. Zhang XL, Yan ZW, Sheng WW, Xiao J, Zhang ZX, Ye ZB. Activation of hypoxiainducible factor- 1 ameliorates postischemic renal injury via inducible nitric oxide synthase. Mol Cell Biochem. 2011;358(1-2):287-95.

75. Jiang N, Zhao H, Han Y, Li L, Xiong S, Zeng L, et al. HIF-1alpha ameliorates tubular injury in diabetic nephropathy via $\mathrm{HO}-1$-mediated control of mitochondrial dynamics. Cell Prolif. 2020;53(11):e12909.

76. Ockaili R, Natarajan R, Salloum F, Fisher BJ, Jones D, Fowler AA, 3rd, et al. HIF-1 activation attenuates postischemic myocardial injury: role for heme oxygenase1 in modulating microvascular chemokine generation. Am J Physiol Heart Circ Physiol. 2005;289(2):H542-8.

77. Gozzelino R, Jeney V, Soares MP. Mechanisms of cell protection by heme oxygenase-1. Annu Rev Pharmacol Toxicol. 2010;50:323-54.

78. Gazzin S, Vitek L, Watchko J, Shapiro SM, Tiribelli C. A Novel Perspective on the Biology of Bilirubin in Health and Disease. Trends Mol Med. 2016;22(9):758-68.

79. Sandau KB, Fandrey J, Brune B. Accumulation of HIF-1alpha under the influence of nitric oxide. Blood. 2001;97(4):1009-15.

80. Sogawa K, Numayama-Tsuruta K, Ema M, Abe M, Abe H, Fujii-Kuriyama Y. Inhibition of hypoxia-inducible factor 1 activity by nitric oxide donors in hypoxia. Proc Natl Acad Sci U S A. 1998;95(13):7368-73.

81. Hagen T, Taylor CT, Lam F, Moncada S. Redistribution of intracellular oxygen in hypoxia by nitric oxide: effect on HIF1alpha. Science. 2003;302(5652):1975-8.

82. Pan Y, Mansfield KD, Bertozzi CC, Rudenko V, Chan DA, Giaccia AJ, et al. Multiple factors affecting cellular redox status and energy metabolism modulate hypoxia-inducible factor prolyl hydroxylase activity in vivo and in vitro. Mol Cell Biol. 2007;27(3):912-25.

83. Huang LE, Willmore WG, Gu J, Goldberg MA, Bunn HF. Inhibition of hypoxiainducible factor 1 activation by carbon monoxide and nitric oxide. Implications for oxygen sensing and signaling. J Biol Chem. 1999;274(13):9038-44. 
84. Chua YL, Dufour E, Dassa EP, Rustin P, Jacobs HT, Taylor CT, et al. Stabilization of hypoxia-inducible factor-1alpha protein in hypoxia occurs independently of mitochondrial reactive oxygen species production. J Biol Chem. 2010;285(41):31277-84.

85. Kaewpila S, Venkataraman S, Buettner GR, Oberley LW. Manganese superoxide dismutase modulates hypoxia-inducible factor-1 alpha induction via superoxide. Cancer Res. 2008;68(8):2781-8.

86. Brunelle JK, Bell EL, Quesada NM, Vercauteren K, Tiranti V, Zeviani M, et al. Oxygen sensing requires mitochondrial ROS but not oxidative phosphorylation. Cell metabolism. 2005;1(6):409-14.

87. Guzy RD, Hoyos B, Robin E, Chen H, Liu L, Mansfield KD, et al. Mitochondrial complex III is required for hypoxia-induced ROS production and cellular oxygen sensing. Cell metabolism. 2005;1(6):401-8.

88. Mansfield KD, Guzy RD, Pan Y, Young RM, Cash TP, Schumacker PT, et al. Mitochondrial dysfunction resulting from loss of cytochrome $c$ impairs cellular oxygen sensing and hypoxic HIF-alpha activation. Cell metabolism. 2005;1(6):393-9.

89. Brune B, Zhou J. Nitric oxide and superoxide: interference with hypoxic signaling. Cardiovasc Res. 2007;75(2):275-82.

90. Thomas DD, Ridnour LA, Espey MG, Donzelli S, Ambs S, Hussain SP, et al. Superoxide fluxes limit nitric oxide-induced signaling. J Biol Chem. 2006;281(36):25984-93.

91. Basak P, Sadhukhan P, Sarkar P, Sil PC. Perspectives of the Nrf-2 signaling pathway in cancer progression and therapy. Toxicology reports. 2017;4:306-18.

92. Baird L, Lleres D, Swift S, Dinkova-Kostova AT. Regulatory flexibility in the Nrf2mediated stress response is conferred by conformational cycling of the Keap1-Nrf2 protein complex. Proc Natl Acad Sci U S A. 2013;110(38):15259-64.

93. Suzuki T, Yamamoto M. Molecular basis of the Keap1-Nrf2 system. Free Radic Biol Med. 2015;88(Pt B):93-100.

94. Leonard MO, Kieran NE, Howell K, Burne MJ, Varadarajan R, Dhakshinamoorthy $\mathrm{S}$, et al. Reoxygenation-specific activation of the antioxidant transcription factor Nrf2 mediates cytoprotective gene expression in ischemiareperfusion injury. FASEB J. 2006;20(14):2624-6.

95. Hirayama A, Nagase S. Electron paramagnetic resonance imaging of oxidative stress in renal disease. Nephron Clin Pract. 2006;103(2):c71-6.

96. Liu M, Grigoryev DN, Crow MT, Haas M, Yamamoto M, Reddy SP, et al. Transcription factor Nrf2 is protective during ischemic and nephrotoxic acute kidney injury in mice. Kidney Int. 2009;76(3):277-85. 
97. Summers DM, Pettigrew GJ. Kidney transplantation following uncontrolled donation after circulatory death. Current opinion in organ transplantation. 2020;25(2):144-50.

98. Hessheimer AJ, Billault C, Barrou B, Fondevila C. Hypothermic or normothermic abdominal regional perfusion in high-risk donors with extended warm ischemia times: impact on outcomes? Transpl Int. 2015;28(6):700-7.

99. Barrou B, Billault C, Nicolas-Robin A. The use of extracorporeal membranous oxygenation in donors after cardiac death. Current opinion in organ transplantation. 2013;18(2):148-53.

100. Kerforne T, Allain G, Giraud S, Bon D, Ameteau V, Couturier P, et al. Defining the optimal duration for normothermic regional perfusion in the kidney donor: A porcine preclinical study. Am J Transplant. 2019;19(3):737-51.

101. Niemann CU, Feiner J, Swain S, Bunting S, Friedman M, Crutchfield M, et al. Therapeutic Hypothermia in Deceased Organ Donors and Kidney-Graft Function. N Engl J Med. 2015;373(5):405-14.

102. O'Callaghan JM, Morgan RD, Knight SR, Morris PJ. Systematic review and meta-analysis of hypothermic machine perfusion versus static cold storage of kidney allografts on transplant outcomes. Br J Surg. 2013;100(8):991-1001.

103. Saba H, Munusamy S, Macmillan-Crow LA. Cold preservation mediated renal injury: involvement of mitochondrial oxidative stress. Ren Fail. 2008;30(2):125-33.

104. Lodhi SA, Lamb KE, Uddin I, Meier-Kriesche HU. Pulsatile pump decreases risk of delayed graft function in kidneys donated after cardiac death. Am J Transplant. 2012;12(10):2774-80.

105. Moers C, Smits JM, Maathuis MH, Treckmann J, van Gelder F, Napieralski BP, et al. Machine perfusion or cold storage in deceased-donor kidney transplantation. N Engl J Med. 2009;360(1):7-19.

106. Chatauret N, Coudroy R, Delpech PO, Vandebrouck C, Hosni S, Scepi M, et al. Mechanistic analysis of nonoxygenated hypothermic machine perfusion's protection on warm ischemic kidney uncovers greater eNOS phosphorylation and vasodilation. Am J Transplant. 2014;14(11):2500-14.

107. Mallet V, Dutheil D, Polard V, Rousselot M, Leize E, Hauet T, et al. Dose-ranging study of the performance of the natural oxygen transporter HEMO2 Life in organ preservation. Artif Organs. 2014;38(8):691-701.

108. Thuillier R, Dutheil D, Trieu MT, Mallet V, Allain G, Rousselot M, et al. Supplementation with a new therapeutic oxygen carrier reduces chronic fibrosis and organ dysfunction in kidney static preservation. Am J Transplant. 2011;11(9):1845-60. 
109. Debout A, Foucher Y, Trebern-Launay K, Legendre C, Kreis H, Mourad G, et al. Each additional hour of cold ischemia time significantly increases the risk of graft failure and mortality following renal transplantation. Kidney Int. 2015;87(2):343-9.

110. Dugbartey GJ, Bouma HR, Saha MN, Lobb I, Henning RH, Sener A. A Hibernation-Like State for Transplantable Organs: Is Hydrogen Sulfide Therapy the Future of Organ Preservation? Antioxid Redox Signal. 2018;28(16):1503-15.

111. Li L, Rose P, Moore PK. Hydrogen sulfide and cell signaling. Annu Rev Pharmacol Toxicol. 2011;51:169-87.

112. Koning AM, Frenay AR, Leuvenink HG, van Goor H. Hydrogen sulfide in renal physiology, disease and transplantation--the smell of renal protection. Nitric Oxide. 2015;46:37-49.

113. Lobb I, Davison M, Carter D, Liu W, Haig A, Gunaratnam L, et al. Hydrogen Sulfide Treatment Mitigates Renal Allograft Ischemia-Reperfusion Injury during Cold Storage and Improves Early Transplant Kidney Function and Survival Following Allogeneic Renal Transplantation. J Urol. 2015;194(6):1806-15.

114. Lobb I, Mok A, Lan Z, Liu W, Garcia B, Sener A. Supplemental hydrogen sulphide protects transplant kidney function and prolongs recipient survival after prolonged cold ischaemia-reperfusion injury by mitigating renal graft apoptosis and inflammation. BJU Int. 2012;110(11 Pt C):E1187-95.

115. Szabo C, Papapetropoulos A. International Union of Basic and Clinical Pharmacology. ClI: Pharmacological Modulation of H2S Levels: H2S Donors and H2S Biosynthesis Inhibitors. Pharmacol Rev. 2017;69(4):497-564.

116. Murry CE, Jennings RB, Reimer KA. Preconditioning with ischemia: a delay of lethal cell injury in ischemic myocardium. Circulation. 1986;74(5):1124-36.

117. Toosy N, McMorris EL, Grace PA, Mathie RT. Ischaemic preconditioning protects the rat kidney from reperfusion injury. BJU Int. 1999;84(4):489-94.

118. Kharbanda RK, Nielsen TT, Redington AN. Translation of remote ischaemic preconditioning into clinical practice. Lancet. 2009;374(9700):1557-65.

119. Torras J, Herrero-Fresneda I, Lloberas N, Riera M, Ma Cruzado J, Ma Grinyo J. Promising effects of ischemic preconditioning in renal transplantation. Kidney Int. 2002;61(6):2218-27 .

120. Soendergaard P, Krogstrup NV, Secher NG, Ravlo K, Keller AK, Toennesen E, et al. Improved GFR and renal plasma perfusion following remote ischaemic conditioning in a porcine kidney transplantation model. Transpl Int. 2012;25(9):100212.

121. Yoon YE, Lee KS, Choi KH, Kim KH, Yang SC, Han WK. Preconditioning strategies for kidney ischemia reperfusion injury: implications of the "time-window" in remote ischemic preconditioning. PLoS One. 2015;10(4):e0124130. 
122. Nadarajah L, Yaqoob MM, McCafferty K. Ischemic conditioning in solid organ transplantation: is it worth giving your right arm for? Curr Opin Nephrol Hypertens. 2017;26(6):467-76.

123. MacAllister R, Clayton T, Knight R, Robertson S, Nicholas J, Motwani M, et al. REmote preconditioning for Protection Against Ischaemia-Reperfusion in renal transplantation (REPAIR): a multicentre, multinational, double-blind, factorial designed randomised controlled trial. Efficacy and Mechanism Evaluation. Southampton (UK)2015.

124. Veighey KV, Nicholas JM, Clayton T, Knight R, Robertson S, Dalton N, et al. Early remote ischaemic preconditioning leads to sustained improvement in allograft function after live donor kidney transplantation: long-term outcomes in the REnal Protection Against Ischaemia-Reperfusion in transplantation (REPAIR) randomised trial. Br J Anaesth. 2019;123(5):584-91.

125. Tauc M, Melis N, Bourourou M, Giraud S, Hauet T, Blondeau N. A new pharmacological preconditioning-based target: from drosophila to kidney transplantation. Conditioning Medicine. 2019;2(2):69-74.

126. Hernandez F, Menendez S, Wong R. Decrease of blood cholesterol and stimulation of antioxidative response in cardiopathy patients treated with endovenous ozone therapy. Free Radic Biol Med. 1995;19(1):115-9.

127. Tirelli U, Cirrito C, Pavanello M, Piasentin C, Lleshi A, Taibi R. Ozone therapy in 65 patients with fibromyalgia: an effective therapy. Eur Rev Med Pharmacol Sci. 2019;23(4):1786-8.

128. Bocci V. Does ozone therapy normalize the cellular redox balance? Implications for therapy of human immunodeficiency virus infection and several other diseases. Med Hypotheses. 1996;46(2):150-4.

129. Ajamieh H, Merino N, Candelario-Jalil E, Menendez S, Martinez-Sanchez G, Re $\mathrm{L}$, et al. Similar protective effect of ischaemic and ozone oxidative preconditionings in liver ischaemia/reperfusion injury. Pharmacol Res. 2002;45(4):333-9.

130. Barber E, Menendez S, Leon OS, Barber MO, Merino N, Calunga JL, et al. Prevention of renal injury after induction of ozone tolerance in rats submitted to warm ischaemia. Mediators Inflamm. 1999;8(1):37-41.

131. Chen H, Xing B, Liu X, Zhan B, Zhou J, Zhu H, et al. Similarities between ozone oxidative preconditioning and ischemic preconditioning in renal ischemia/reperfusion injury. Arch Med Res. 2008;39(2):169-78.

132. Sethi K, Rao K, Bolton D, Patel O, Ischia J. Targeting HIF-1alpha to Prevent Renal Ischemia-Reperfusion Injury: Does It Work? Int J Cell Biol. 2018;2018:9852791.

133. Kan WC, Chien CC, Wu CC, Su SB, Hwang JC, Wang HY. Comparison of lowdose deferoxamine versus standard-dose deferoxamine for treatment of aluminium overload among haemodialysis patients. Nephrol Dial Transplant. 2010;25(5):1604-8. 
134. Richardson DR. The controversial role of deferiprone in the treatment of thalassemia. J Lab Clin Med. 2001;137(5):324-9.

135. Paller MS, Hedlund BE. Role of iron in postischemic renal injury in the rat. Kidney Int. 1988;34(4):474-80.

136. Sharma S, Leaf DE. Iron Chelation as a Potential Therapeutic Strategy for AKI Prevention. J Am Soc Nephrol. 2019;30(11):2060-71.

137. Walker VJ, Agarwal A. Targeting Iron Homeostasis in Acute Kidney Injury. Semin Nephrol. 2016;36(1):62-70.

138. Bulucu F, Oktenli C, Kenar L, Koc B, Ocal R, Karadurmus N, et al. Detrimental effects of $\mathrm{N}$-acetylcysteine plus desferoxamine combination in an experimental nephrotic syndrome model. Int J Toxicol. 2007;26(6):525-32.

139. Clajus C, Becker JU, Stichtenoth DO, Wortmann J, Schwarz A, Kielstein JT. Acute kidney injury due to deferoxamine in a renal transplant patient. Nephrol Dial Transplant. 2008;23(3):1061-4.

140. Oh SW, Lee YM, Kim S, Chin HJ, Chae DW, Na KY. Cobalt chloride attenuates oxidative stress and inflammation through NF-kappaB inhibition in human renal proximal tubular epithelial cells. J Korean Med Sci. 2014;29 Suppl 2:S139-45.

141. Matsumoto M, Makino $\mathrm{Y}$, Tanaka T, Tanaka H, Ishizaka N, Noiri E, et al. Induction of renoprotective gene expression by cobalt ameliorates ischemic injury of the kidney in rats. J Am Soc Nephrol. 2003;14(7):1825-32.

142. Finley BL, Unice KM, Kerger BD, Otani JM, Paustenbach DJ, Galbraith DA, et al. 31-day study of cobalt(II) chloride ingestion in humans: pharmacokinetics and clinical effects. J Toxicol Environ Health A. 2013;76(21):1210-24.

143. Rosenberger C, Rosen S, Shina A, Frei U, Eckardt KU, Flippin LA, et al. Activation of hypoxia-inducible factors ameliorates hypoxic distal tubular injury in the isolated perfused rat kidney. Nephrol Dial Transplant. 2008;23(11):3472-8.

144. Bernhardt WM, Gottmann U, Doyon F, Buchholz B, Campean V, Schodel J, et al. Donor treatment with a PHD-inhibitor activating HIFs prevents graft injury and prolongs survival in an allogenic kidney transplant model. Proc Natl Acad Sci U S A. 2009;106(50):21276-81.

145. Del Balzo U, Signore PE, Walkinshaw G, Seeley TW, Brenner MC, Wang Q, et al. Nonclinical Characterization of the Hypoxia-Inducible Factor Prolyl Hydroxylase Inhibitor Roxadustat, a Novel Treatment of Anemia of Chronic Kidney Disease. J Pharmacol Exp Ther. 2020;374(2):342-53.

146. Provenzano $\mathrm{R}$, Besarab A, Sun $\mathrm{CH}$, Diamond SA, Durham JH, Cangiano JL, et al. Oral Hypoxia-Inducible Factor Prolyl Hydroxylase Inhibitor Roxadustat (FG-4592) for the Treatment of Anemia in Patients with CKD. Clin J Am Soc Nephrol. 2016;11(6):982-91. 
147. Yang $Y, Y u X$, Zhang $Y$, Ding G, Zhu C, Huang S, et al. Hypoxia-inducible factor prolyl hydroxylase inhibitor roxadustat (FG-4592) protects against cisplatin-induced acute kidney injury. Clin Sci (Lond). 2018;132(7):825-38.

148. To C, Ringelberg CS, Royce DB, Williams CR, Risingsong R, Sporn MB, et al. Dimethyl fumarate and the oleanane triterpenoids, CDDO-imidazolide and CDDOmethyl ester, both activate the Nrf2 pathway but have opposite effects in the A/J model of lung carcinogenesis. Carcinogenesis. 2015;36(7):769-81.

149. Liu M, Reddy NM, Higbee EM, Potteti HR, Noel S, Racusen L, et al. The Nrf2 triterpenoid activator, CDDO-imidazolide, protects kidneys from ischemia-reperfusion injury in mice. Kidney Int. 2014;85(1):134-41.

150. Nezu M, Souma T, Yu L, Suzuki T, Saigusa D, Ito S, et al. Transcription factor Nrf2 hyperactivation in early-phase renal ischemia-reperfusion injury prevents tubular damage progression. Kidney Int. 2017;91(2):387-401.

151. Kocak C, Kocak FE, Akcilar R, Bayat Z, Aras B, Metineren MH, et al. Effects of captopril, telmisartan and bardoxolone methyl (CDDO-Me) in ischemia-reperfusioninduced acute kidney injury in rats: an experimental comparative study. Clin Exp Pharmacol Physiol. 2016;43(2):230-41.

152. Pergola PE, Krauth M, Huff JW, Ferguson DA, Ruiz S, Meyer CJ, et al. Effect of bardoxolone methyl on kidney function in patients with T2D and Stage 3b-4 CKD. Am J Nephrol. 2011;33(5):469-76.

153. Pergola PE, Raskin P, Toto RD, Meyer CJ, Huff JW, Grossman EB, et al. Bardoxolone methyl and kidney function in CKD with type 2 diabetes. N Engl J Med. 2011;365(4):327-36.

154. de Zeeuw D, Akizawa T, Audhya P, Bakris GL, Chin M, Christ-Schmidt H, et al. Bardoxolone methyl in type 2 diabetes and stage 4 chronic kidney disease. $\mathrm{N}$ Engl J Med. 2013;369(26):2492-503.

155. Liebman SE, Le TH. Eat Your Broccoli: Oxidative Stress, NRF2, and Sulforaphane in Chronic Kidney Disease. Nutrients. 2021;13(1).

156. Dinkova-Kostova AT, Fahey JW, Kostov RV, Kensler TW. KEAP1 and Done? Targeting the NRF2 Pathway with Sulforaphane. Trends in food science \& technology. 2017;69(Pt B):257-69.

157. Yoon HY, Kang NI, Lee HK, Jang KY, Park JW, Park BH. Sulforaphane protects kidneys against ischemia-reperfusion injury through induction of the Nrf2-dependent phase 2 enzyme. Biochem Pharmacol. 2008;75(11):2214-23.

158. Shokeir AA, Barakat N, Hussein AM, Awadalla A, Harraz AM, Khater S, et al. Activation of Nrf2 by ischemic preconditioning and sulforaphane in renal ischemia/reperfusion injury: a comparative experimental study. Physiol Res. 2015;64(3):313-23. 
159. Cekauskas A, Bruns $H$, Manikas M, Herr I, Gross ML, Zorn M, et al. Sulforaphane decreases kidney injury after transplantation in rats: role of mitochondrial damage. Ann Transplant. 2013;18:488-96.

160. Lv D, Zhou Q, Xia Y, You X, Zhao Z, Li Y, et al. The Association Between Oxidative Stress Alleviation via Sulforaphane-Induced Nrf2-HO-1/NQO-1 Signaling Pathway Activation and Chronic Renal Allograft Dysfunction Improvement. Kidney Blood Press Res. 2018;43(1):191-205.

161. Giraud S, Kerforne T, Zely J, Ameteau V, Couturier P, Tauc M, et al. The inhibition of elF5A hypusination by GC7, a preconditioning protocol to prevent brain death-induced renal injuries in a preclinical porcine kidney transplantation model. Am J Transplant. 2020;20(12):3326-40.

162. Kim M, Ham A, Kim JY, Brown KM, D'Agati VD, Lee HT. The volatile anesthetic isoflurane induces ecto-5'-nucleotidase (CD73) to protect against renal ischemia and reperfusion injury. Kidney Int. 2013;84(1):90-103.

163. Lee HT, Kim M, Jan M, Emala CW. Anti-inflammatory and antinecrotic effects of the volatile anesthetic sevoflurane in kidney proximal tubule cells. Am J Physiol Renal Physiol. 2006;291(1):F67-78.

164. Lee HT, Ota-Setlik A, Fu Y, Nasr SH, Emala CW. Differential protective effects of volatile anesthetics against renal ischemia-reperfusion injury in vivo. Anesthesiology. 2004;101(6):1313-24.

165. Yang S, Chou WP, Pei L. Effects of propofol on renal ischemia/reperfusion injury in rats. Exp Ther Med. 2013;6(5):1177-83.

166. Yuzer H, Yuzbasioglu MF, Ciralik H, Kurutas EB, Ozkan OV, Bulbuloglu E, et al. Effects of intravenous anesthetics on renal ischemia/reperfusion injury. Ren Fail. 2009;31(4):290-6.

167. Saricaoglu F, Akinci SB, Oc B, Kanbak M, Akbulut B, Celebioglu B. The effect of halothane, isoflurane, sevoflurane and propofol infusion on renal function after coronary artery bypass surgery. Middle East J Anaesthesiol. 2006;18(5):955-64.

168. Ammar AS, Mahmoud KM. Comparative effect of propofol versus sevoflurane on renal ischemia/reperfusion injury after elective open abdominal aortic aneurysm repair. Saudi journal of anaesthesia. 2016;10(3):301-7.

169. Yoo YC, Shim JK, Song Y, Yang SY, Kwak YL. Anesthetics influence the incidence of acute kidney injury following valvular heart surgery. Kidney Int. 2014;86(2):414-22.

170. Sanchez-Conde P, Rodriguez-Lopez JM, Nicolas JL, Lozano FS, Garcia-Criado FJ, Cascajo C, et al. The comparative abilities of propofol and sevoflurane to modulate inflammation and oxidative stress in the kidney after aortic cross-clamping. Anesth Analg. 2008;106(2):371-8, table of contents. 
171. Ma D, Lim T, Xu J, Tang H, Wan $\mathrm{Y}$, Zhao H, et al. Xenon preconditioning protects against renal ischemic-reperfusion injury via HIF-1alpha activation. J Am Soc Nephrol. 2009;20(4):713-20.

172. Stevanovic A, Schaefer P, Coburn M, Rossaint R, Stoppe C, Boor P, et al. Renal function following xenon anesthesia for partial nephrectomy-An explorative analysis of a randomized controlled study. PLoS One. 2017;12(7):e0181022.

173. Altintas R, Polat A, Vardi N, Oguz F, Beytur A, Sagir M, et al. The protective effects of apocynin on kidney damage caused by renal ischemia/reperfusion. $J$ Endourol. 2013;27(5):617-24.

174. Choi EK, Jung H, Kwak KH, Yeo J, Yi SJ, Park CY, et al. Effects of Allopurinol and Apocynin on Renal Ischemia-Reperfusion Injury in Rats. Transplant Proc. 2015;47(6):1633-8.

175. Choi EK, Jung H, Kwak KH, Yi SJ, Lim JA, Park SH, et al. Inhibition of Oxidative Stress in Renal Ischemia-Reperfusion Injury. Anesth Analg. 2017;124(1):204-13.

176. Tsuda H, Kawada N, Kaimori JY, Kitamura H, Moriyama T, Rakugi H, et al. Febuxostat suppressed renal ischemia-reperfusion injury via reduced oxidative stress. Biochem Biophys Res Commun. 2012;427(2):266-72.

177. Fujii K, Kubo A, Miyashita K, Sato M, Hagiwara A, Inoue H, et al. Xanthine oxidase inhibitor ameliorates postischemic renal injury in mice by promoting resynthesis of adenine nucleotides. $\mathrm{JCl}$ insight. 2019;4(22).

178. Prieto-Moure B, Caraben-Redano A, Aliena-Valero A, Cejalvo D, Toledo AH, Flores-Bellver M, et al. Allopurinol in renal ischemia. J Invest Surg. 2014;27(5):304-16.

179. Sampaio TL, Menezes RR, da Costa MF, Meneses GC, Arrieta MC, Chaves Filho AJ, et al. Nephroprotective effects of (-)-alpha-bisabolol against ischemicreperfusion acute kidney injury. Phytomedicine. 2016;23(14):1843-52.

180. Sampaio TL, Menezes R, Lima DB, Costa Silva RA, de Azevedo IEP, Magalhaes EP, et al. Involvement of NADPH-oxidase enzyme in the nephroprotective effect of (-)-alpha-bisabolol on HK2 cells exposed to ischemia - Reoxygenation. Eur $\mathrm{J}$ Pharmacol. 2019;855:1-9.

181. Yamato M, Kawano K, Yamanaka Y, Saiga M, Yamada K. TEMPOL increases $\mathrm{NAD}(+)$ and improves redox imbalance in obese mice. Redox biology. 2016;8:316-22.

182. Aksu U, Ergin B, Bezemer R, Kandil A, Milstein DM, Demirci-Tansel C, et al. Scavenging reactive oxygen species using tempol in the acute phase of renal ischemia/reperfusion and its effects on kidney oxygenation and nitric oxide levels. Intensive care medicine experimental. 2015;3(1):57.

183. Ergin B, Bezemer R, Kandil A, Demirci-Tansel C, Ince C. TEMPOL has limited protective effects on renal oxygenation and hemodynamics but reduces kidney 
damage and inflammation in a rat model of renal ischemia/reperfusion by aortic clamping. Journal of clinical and translational research. 2015;1(2):1-13.

184. Lucas ML, Rhoden CR, Rhoden EL, Zettler CG, Mattos AA. Effects of L-arginine and L-NAME on ischemia-reperfusion in rat liver. Acta Cir Bras. 2015;30(5):345-52.

185. Ghasemi M, Nematbakhsh M, Daneshmand F, Moeini M, Talebi A. Role of nitric oxide in kidney and liver (as distance organ) function in bilateral renal ischemiareperfusion: Effect of L-Arginine and NG-nitro-L-Arginine methyl ester. Advanced biomedical research. 2015;4:233.

186. Guven A, Uysal B, Akgul O, Cermik H, Gundogdu G, Surer I, et al. Scavenging of peroxynitrite reduces renal ischemia/reperfusion injury. Ren Fail. 2008;30(7):74754.

187. Dixon SJ, Lemberg KM, Lamprecht MR, Skouta R, Zaitsev EM, Gleason CE, et al. Ferroptosis: an iron-dependent form of nonapoptotic cell death. Cell. 2012;149(5):1060-72.

188. Linkermann A, Skouta R, Himmerkus N, Mulay SR, Dewitz C, De Zen F, et al. Synchronized renal tubular cell death involves ferroptosis. Proc Natl Acad Sci U S A. 2014;111(47):16836-41.

189. Skouta R, Dixon SJ, Wang J, Dunn DE, Orman M, Shimada K, et al. Ferrostatins inhibit oxidative lipid damage and cell death in diverse disease models. J Am Chem Soc. 2014;136(12):4551-6.

190. Wang Y, Quan F, Cao Q, Lin Y, Yue C, Bi R, et al. Quercetin alleviates acute kidney injury by inhibiting ferroptosis. Journal of advanced research. 2021;28:231-43.

191. Lin HC, Cheng TH, Chen YC, Juan SH. Mechanism of heme oxygenase-1 gene induction by quercetin in rat aortic smooth muscle cells. Pharmacology. 2004;71(2):107-12.

192. Shoskes D, Lapierre C, Cruz-Correa M, Muruve N, Rosario R, Fromkin B, et al. Beneficial effects of the bioflavonoids curcumin and quercetin on early function in cadaveric renal transplantation: a randomized placebo controlled trial. Transplantation. 2005;80(11):1556-9.

193. Vigne $\mathrm{P}$, Frelin $\mathrm{C}$. The role of polyamines in protein-dependent hypoxic tolerance of Drosophila. BMC Physiol. 2008;8:22.

194. Park MH, Nishimura K, Zanelli CF, Valentini SR. Functional significance of elF5A and its hypusine modification in eukaryotes. Amino Acids. 2010;38(2):491-500.

195. Lee YB, Folk JE. Branched-chain and unsaturated 1,7-diaminoheptane derivatives as deoxyhypusine synthase inhibitors. Bioorg Med Chem. 1998;6(3):25370. 
196. Melis N, Rubera I, Cougnon M, Giraud S, Mograbi B, Belaid A, et al. Targeting elF5A Hypusination Prevents Anoxic Cell Death through Mitochondrial Silencing and Improves Kidney Transplant Outcome. J Am Soc Nephrol. 2017;28(3):811-22.

197. Giraud S, Favreau F, Chatauret N, Thuillier R, Maiga S, Hauet T. Contribution of large pig for renal ischemia-reperfusion and transplantation studies: the preclinical model. J Biomed Biotechnol. 2011;2011:532127.

198. Cougnon M, Carcy R, Melis N, Rubera I, Duranton C, Dumas K, et al. Inhibition of elF5A hypusination reprogrammes metabolism and glucose handling in mouse kidney. Cell Death Dis. 2021;12(4):283.

199. Bourourou M, Gouix E, Melis N, Friard J, Heurteaux C, Tauc M, et al. Inhibition of elF5A hypusination pathway as a new pharmacological target for stroke therapy. J Cereb Blood Flow Metab. 2020:271678X20928882. 


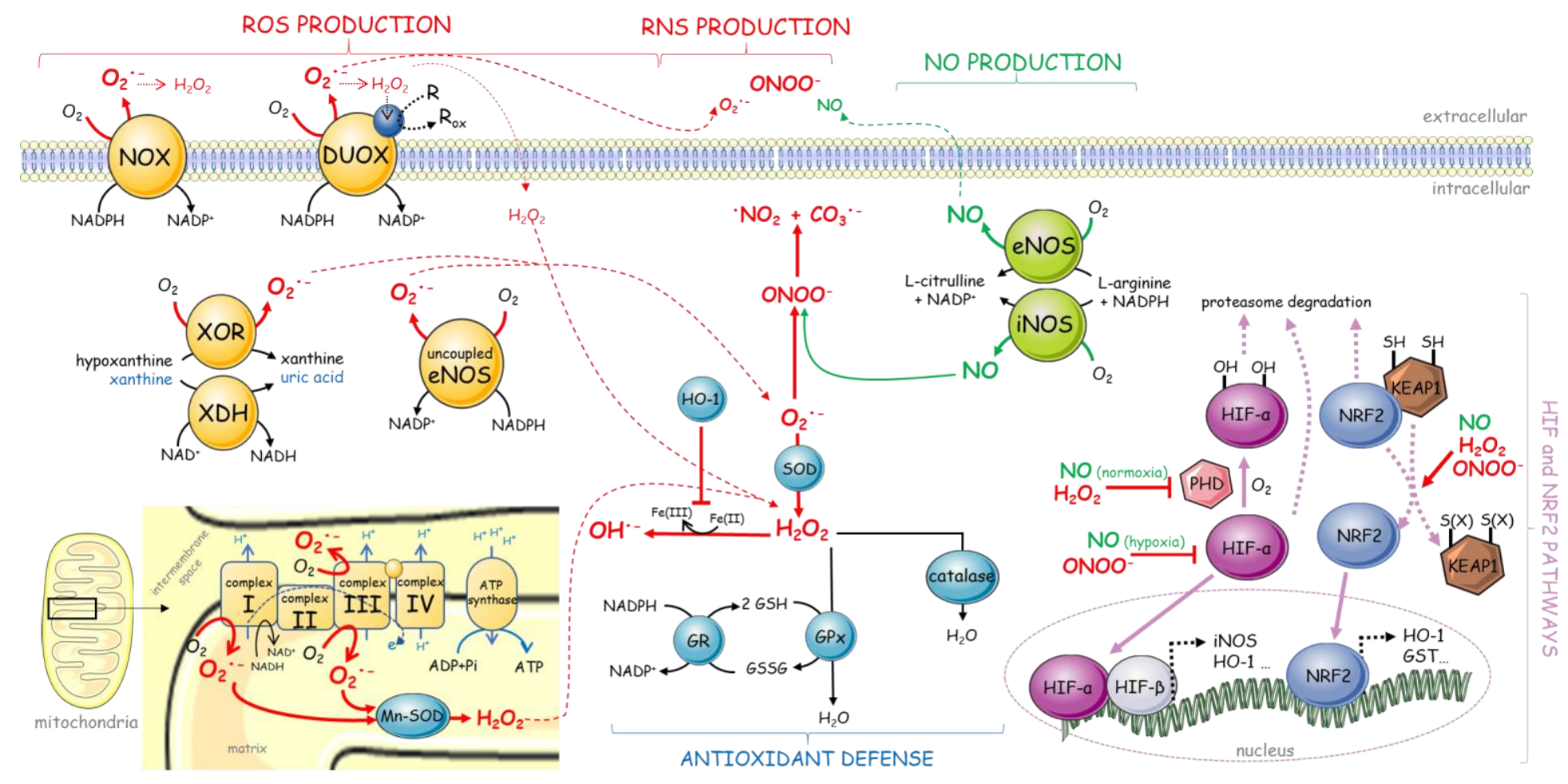

Figure 1. Schematization of the principal oxidative stress components leading to reactive oxygen species (ROS, red/orange), reactive nitrogen species (RNS, red) and nitric oxide (NO, green) production, as well as antioxidant defense (blue) and HIF-1 (purple) pathways. NOX, NADPH oxidase; DUOX, dual oxidase; XOR, xanthine oxidoreductase; XDH, xanthine dehydrogenase; NOS, nitric oxide synthase; SOD, superoxide dismutase; HO, heme oxygenase; GR, glutathione reductase; GPx, glutathione peroxidase; HIF, hypoxia inducible factor; PHD, prolyl-hydroxylase; NRF2, nuclear factor erythroid-2-related factor 2; KEAP1, Kelch-like ECH-associated protein 1; GST, glutathione S-transferase. 


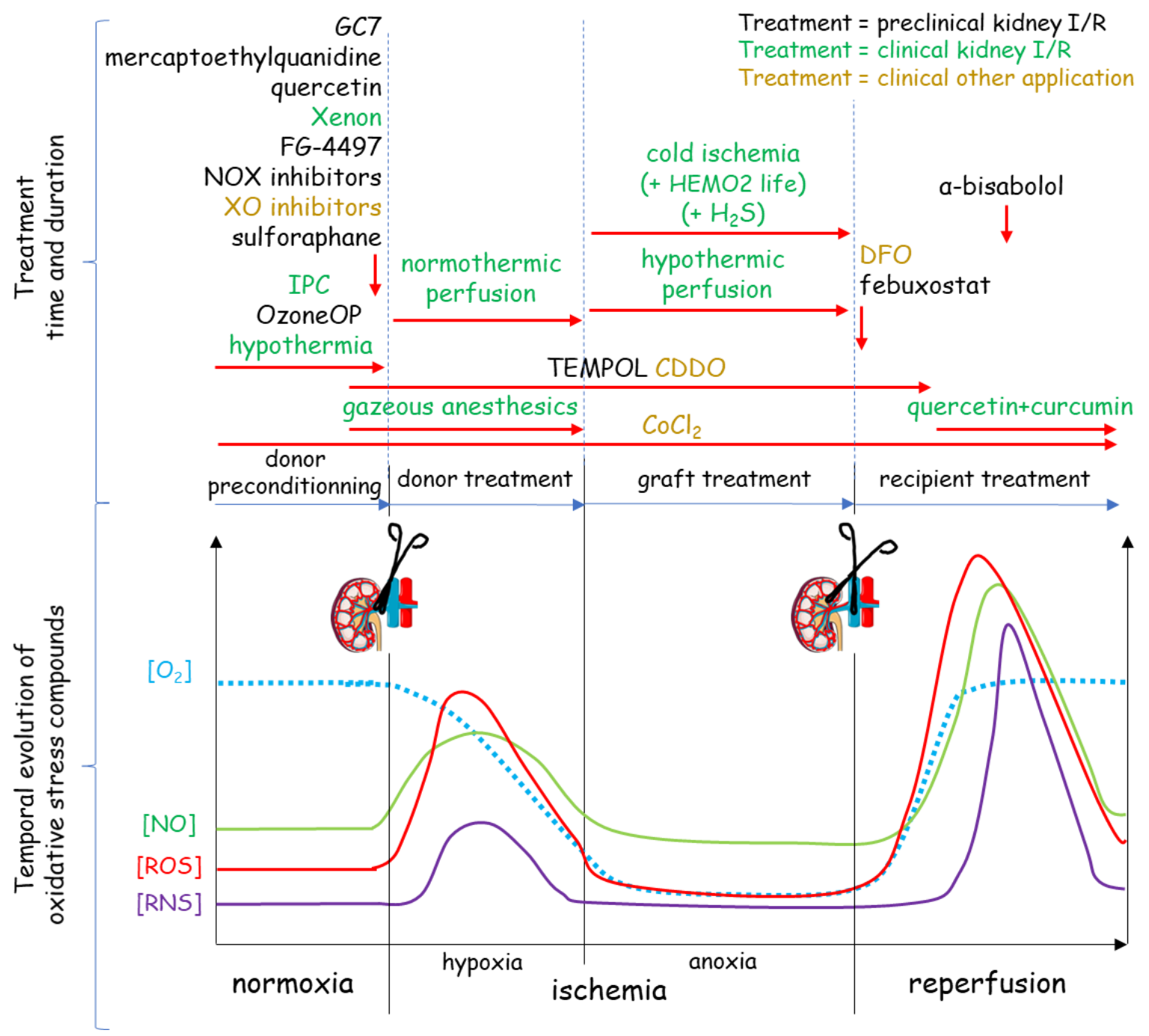

Figure 2. Oxygen availability $\left(\mathrm{O}_{2}\right)$ and reactive species productions (nitric oxide, NO; reactive nitrogen species, RNS; reactive oxygen species, ROS) (lower panel) along kidney transplantation procedure and place and duration of treatments (upper panel) developed only in pre-clinical models (in black) or used in clinic for kidney transplantation (in green) or for other applications (in orange). IPC, ischemic preconditioning; I/R, ischemia/reperfusion. 
A

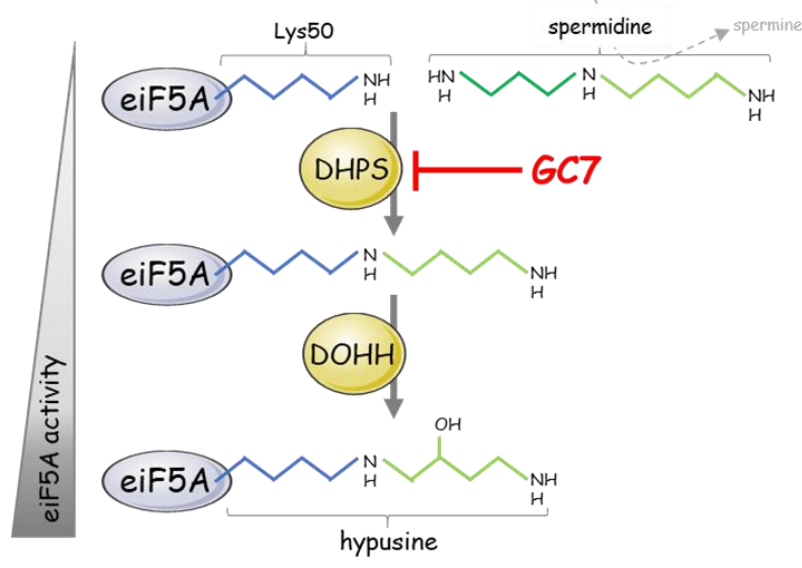

B

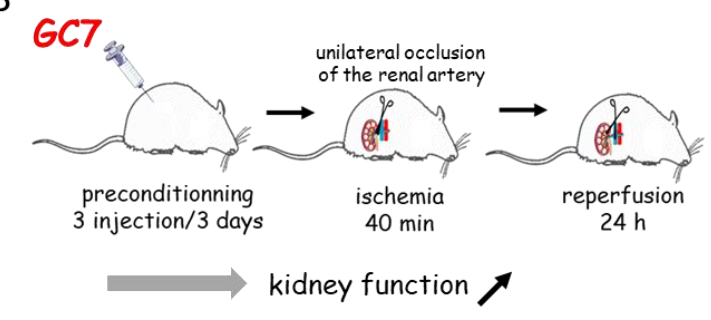

C

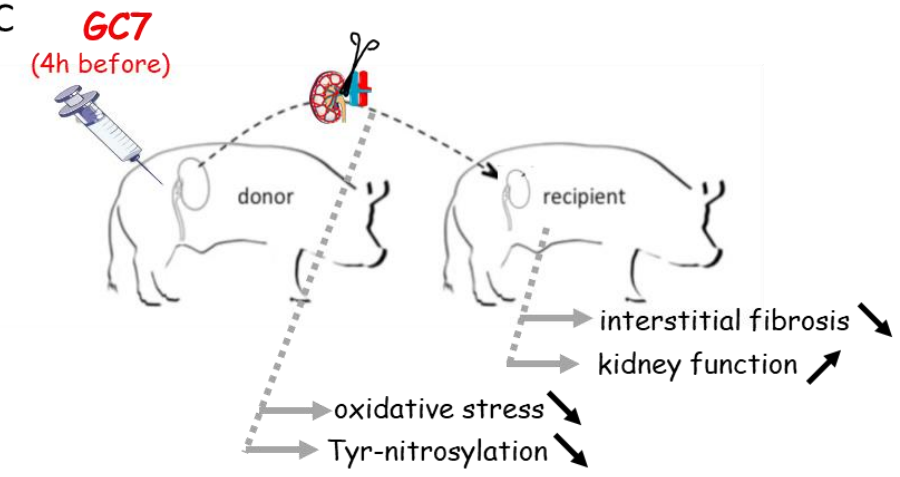

D

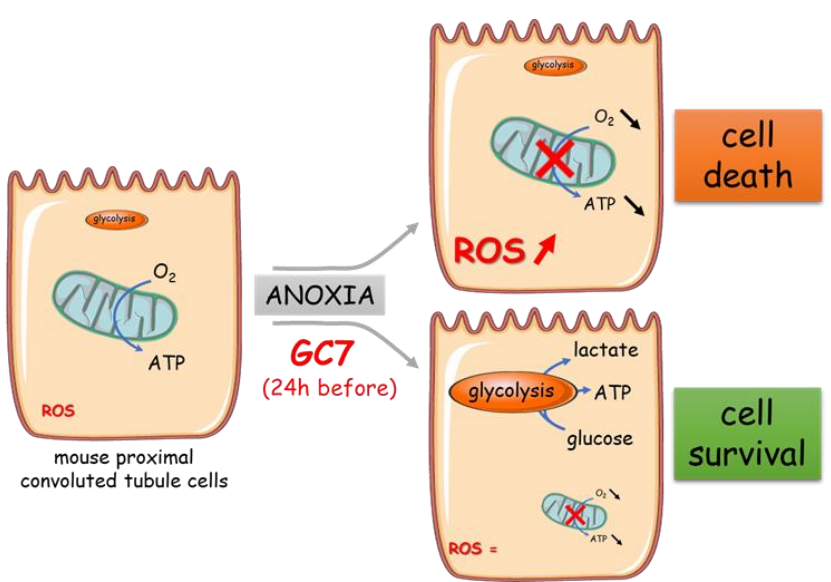

Figure 3. GC7 and its application in kidney I/R. A/ Focus on GC7 interaction with enzymatic cascade leading to activated eiF5A (deoxyhypusine synthase, DHPS; deoxyhypusine hydroxylase, $\mathrm{DOHH}$; eukaryotic translation Initiation Factor 5A, elF5A; N1-guanyl-1,7-diamineoheptane, GC7). B/ GC7 effect in rat model of kidney I/R. C/ GC7 effect in pig preclinical model of kidney transplant. D/ GC7 effect in in vitro kidney cells model of anoxia resistance. 